\title{
The Adhesion-GPCR BAI1 Regulates Synaptogenesis by Controlling the Recruitment of the Par3/Tiam1 Polarity Complex to Synaptic Sites
}

\author{
Joseph G. Duman, ${ }^{1}$ Christopher P. Tzeng, ${ }^{1}$ Yen-Kuei Tu, ${ }^{1,2}$ Tina Munjal, ${ }^{1,5}$ Brandon Schwechter, ${ }^{1}$ Tammy Szu-Yu Ho, ${ }^{3}$ \\ and Kimberley F. Tolias ${ }^{1,4}$ \\ ${ }^{1}$ Department of Neuroscience, ${ }^{2}$ Graduate Program in Cell and Molecular Biology, ${ }^{3}$ Program in Developmental Biology, and ${ }^{4}$ Verna and Marrs McLean \\ Department of Biochemistry and Molecular Biology, Baylor College of Medicine, Houston, Texas 77030, and ${ }^{5}$ Department of Biochemistry and Cell Biology, \\ Rice University, Houston, Texas 77005
}

Excitatory synapses are polarized structures that primarily reside on dendritic spines in the brain. The small GTPase Rac1 regulates the development and plasticity of synapses and spines by modulating actin dynamics. By restricting the Racl-guanine nucleotide exchange factor Tiam1 to spines, the polarity protein Par3 promotes synapse development by spatially controlling Rac1 activation. However, the mechanism for recruiting Par3 to spines is unknown. Here, we identify brain-specific angiogenesis inhibitor 1 (BAI1) as a synaptic adhesion GPCR that is required for spinogenesis and synaptogenesis in mice and rats. We show that BAI1 interacts with Par3/Tiam1 and recruits these proteins to synaptic sites. BAI1 knockdown results in Par3/Tiam1 mislocalization and loss of activated Rac1 and filamentous actin from spines. Interestingly, BAI1 also mediates Rac-dependent engulfment in professional phagocytes through its interaction with a different Rac1-guanine nucleotide exchange factor module, ELMO/DOCK180. However, this interaction is dispensable for BAI1's role in synapse development because a BAI1 mutant that cannot interact with ELMO/DOCK180 rescues spine defects in BAI1-knockdown neurons, whereas a mutant that cannot interact with Par3/Tiam1 rescues neither spine defects nor Par3 localization. Further, overexpression of Tiam1 rescues BAIl knockdown spine phenotypes. These results indicate that BAI1 plays an important role in synaptogenesis that is mechanistically distinct from its role in phagocytosis. Furthermore, our results provide the first example of a cell surface receptor that targets members of the PAR polarity complex to synapses.

\section{Introduction}

Synapses transfer information directionally and are therefore structurally and functionally asymmetric. In the brain, small actin-rich protrusions, called dendritic spines, serve as the primary postsynaptic sites for excitatory synapses (Tada and Sheng, 2006). Spines remodel during development and in response to activity, and changes in spine size and shape typically positively correlate with alterations in the functional properties of resident synapses (Tada and Sheng, 2006; Penzes et al., 2011; Bosch and

\footnotetext{
Received Aug. 20, 2012; revised Jan. 28, 2013; accepted Feb. 28, 2013

Author contributions: J.G.D., C.P.T., and K.F.T. designed research; J.G.D., C.P.T., Y.-K.T., T.M., B.S., and T.S.-Y.H. performed research; J.G.D., C.P.T., and Y.-K.T. analyzed data; J.G.D. and K.F.T. wrote the paper.

This work was supported by National Institutes of Health Grant R01NS062829 to K.F.T. and Grant K01MH086119 to J.G.D., and Mission Connect. We thank J. Forte, D. Grosshans, S. Aamodt, and K. Um for critical reading of this manuscript; the Allen Brain Atlas for images; M. Greenberg and M. Rasband for sharing reagents and expertise; A. Narayanan, S. Mulherkar, and K. Ung for technical advice and assistance; F. Liu for technical and administrative support; K. Firozi for administrative support; K. Ravichandran (University of Virginia) for providing BAl1 • RKR $\rightarrow$ AAA; I. Macara (University of Virginia) for providing Par3 shRNAs; M. Matsuda (Kyoto University) for providing RaichuEV-Rac1; and K. Um for assistance with cell cultures.

The authors declare no competing financial interests.

Correspondence should be addressed to Dr. Kimberley F. Tolias, One Baylor Plaza, MS-BCM295, Houston, TX 77030. E-mail: tolias@bcm.edu.

C. P. Tzeng's present address: Program in Neurobiology, Harvard Medical School, Boston, MA 02115

T. Munjal's present address: School of Medicine, Johns Hopkins University, Baltimore, MD 21287.

DOI:10.1523/JNEUROSCI.3978-12.2013

Copyright $\odot 2013$ the authors $\quad 0270-6474 / 13 / 336964-15 \$ 15.00 / 0$
}

Hayashi, 2012). Because defects in spine and synapse development and/or plasticity are associated with the vast majority of cognitive disorders (Ramakers, 2002; Penzes et al., 2011), it is important to understand how they are formed and remodeled.

The partitioning-defective (PAR) complex is a core determinant of cellular polarity (Ohno, 2001; Welchman et al., 2007). Consisting of Par3, Par6, and atypical protein kinase C, this complex regulates polarized processes, including axon specification (Shi et al., 2003), migration (Spindler and Hartenstein, 2011), and spine and synapse development (Zhang and Macara, 2006, 2008). Many PAR-mediated processes require activation of the GTPase Rac1 by Tiam1, a Rac-specific guanine nucleotide exchange factor (GEF) (Mertens et al., 2006). Par3 recruits Tiam1 to specific sites, resulting in spatially restricted Racl activation and localized cytoskeletal remodeling that is essential for cellular polarity (Mertens et al., 2006). Precise regulation of Rac1 activity at synapses is required for proper spine and synapse development (Tolias et al., 2011). Tiam1 activates Rac1 at synapses, and loss of Tiam1 function in neurons uncouples Racl activation and spinogenesis from glutamate/NMDA receptor signaling and ephrinB/EphB receptor signaling (Tolias et al., 2005, 2007). Par3 recruits Tiam1 to spines, and neuronal knockdown of Par3 delocalizes Tiam1, resulting in Rac1 dysregulation, ectopic spines, and synaptic dysgenesis (Zhang and Macara, 2006). It remains unclear how Par3 itself is recruited to synaptic sites. 


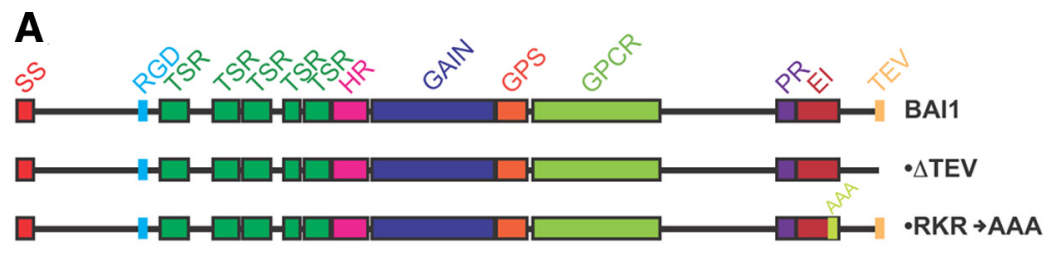

B
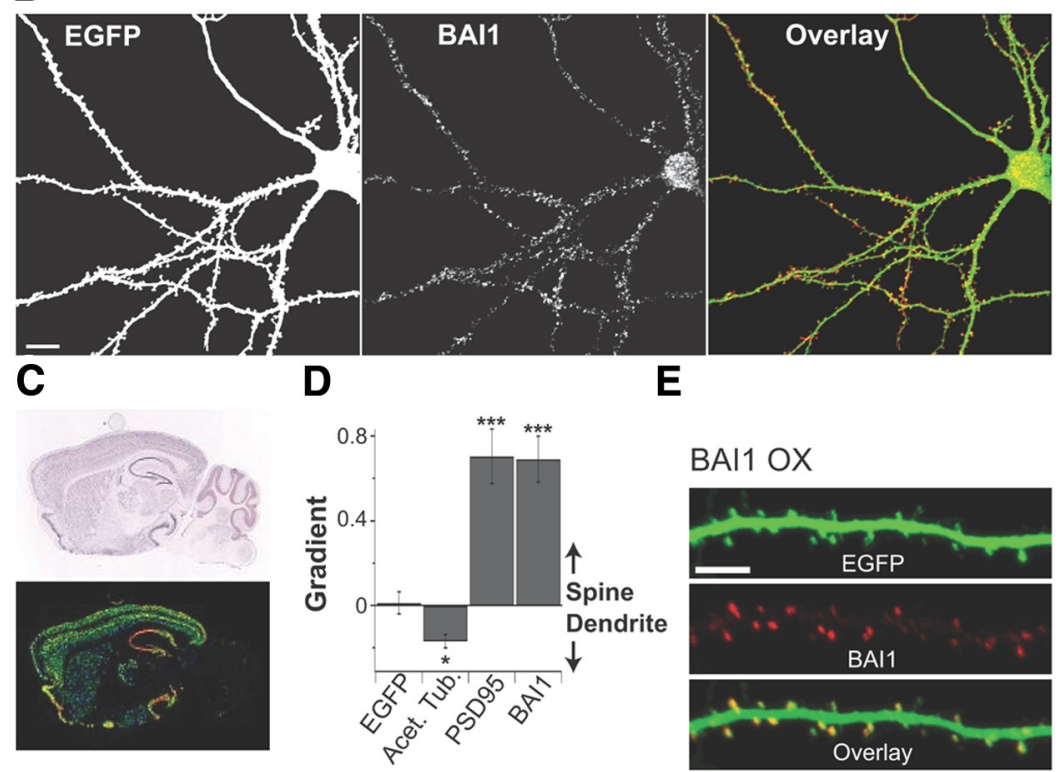

$\mathbf{F}$
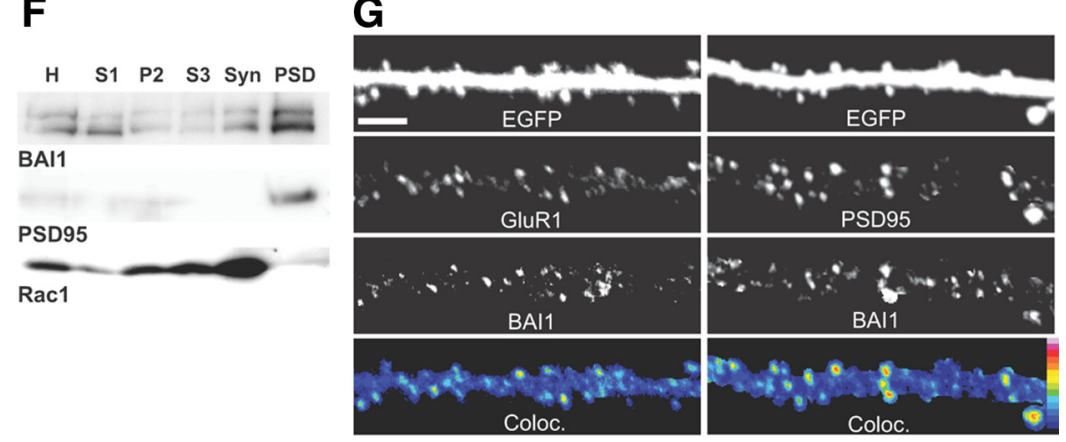

Figure 1. BAI1 is expressed in neurons and localizes to excitatory synapses. $A$, Diagrams depicting the domain structures of BAI1 and BAl1 mutants used in this study. SS, Signal sequence (cleaved); RGD, arginine-glycine-glutamate motif (binds integrins); TSR, thrombospondin type I repeat; HR, hormone receptor domain; GAIN, GPCR- autoproteolysis-inducing domain; GPS, G-protein cleavage site; PR, proline-rich domain; El, ELM0-interacting domain; TEV, threonine-aspartate-valine motif (binds PDZ domains). $B$, The 21 DIV EGFP-expressing rat hippocampal neurons were fixed and stained for BAI1, which localizes to dendritic spines. Image is representative of $>100$ images. Scale bar, $10 \mu \mathrm{m}$. C, In situ hybridization (top) was used to detect BAl1 message in this sagittal section of adult mouse brain. An intensity-coded summary image is on the bottom. There is high expression of BAl1 in the hippocampus and broad expression throughout the cortex. Images courtesy of the Allen Brain Atlas. D, Spine enrichment of various proteins was calculated using gradients as described in Materials and Methods. Data are mean \pm SEM $(n=30 ; N=3)$. E, BAl1 and EGFP were introduced exogenously into rat hippocampal neurons using calcium phosphate at 6 DIV. Neurons were fixed at 21 DIV and stained for BAl1. Images are representative of $>100$ images $(N>10)$. Scale bar, $5 \mu \mathrm{m}$. $\boldsymbol{F}$, Fractions from a PSD preparation were stained against BAI1, PSD95 (positive control), and Rac1 (loading control). The PSD fraction is underloaded (per Rac1) relative to other fractions (H, Homogenate; $S 1,1900 \times g$ supernatant; $P 2,24,000 \times g$ pellet; $S 3,33,000 \times g$ supernatant; Syn, synaptosome fraction). Like PSD95, BAI1 showed significant enrichment in the PSD. G, The 21 DIV EGFP-expressing rat hippocampal neurons were stained for BAI1 and the synaptic proteins GluR1 or PSD95. Colocalization images are encoded using the color scale to the right. Correlation coefficients for these and other markers can be found in Results. Images are representative of 30 neurons $(N=3)$. Scale bar, $5 \mu \mathrm{m}$. Data are mean \pm SEM. ${ }^{*} p<0.05,{ }^{* * *} p<0.001$.

Adhesion GPCRs (A-GPCRs) are a family of GPCRs characterized by long extracellular $\mathrm{N}$-terminal regions containing multiple adhesion domains connected to GPCR moieties by G-protein proteolysis sites (Yona et al., 2008). Although humans have 33 A-GPCRs, little is known of their biology. Brain-specific angiogenesis inhibitor 1 (BAI1) is an A-GPCR that is widely expressed throughout the brain. BAI1 inhibits angiogenesis, and accordingly its suppression is permissive for glioblastoma growth (Zhu et al., 2011). BAI1 also binds to phosphatidylserine and mediates the engulfment of apoptotic cells (Park et al., 2007) and Gram-negative bacteria (Das et al., 2011) by professional macrophages.

Here, we show that BAI1 is required for synaptogenesis in hippocampal and cortical neurons in vitro and in vivo. We demonstrate that BAI1 targets Par3/ Tiam 1 to synaptic sites, which is necessary for proper Racl activation. These results indicate a synaptogenic role for BAI1 by a mechanism completely distinct from those by which it inhibits angiogenesis and promotes phagocytosis. BAIl's control of the localization of Par3/Tiam1 is the first example, to our knowledge, of a cell surface receptor that targets members of the PAR complex to synapses. Therefore, these results represent an important advance in the understanding of both synaptogenesis and the biology of A-GPCRs.

\section{Materials and Methods}

Antibodies. Rabbit polyclonal antibodies against BAI1 (amino acids 1180-1584) and phospho-p21-activated kinase (PAK) were homemade and affinity purified using the SulfoLink Protein Immobilization Kit (Thermo Scientific). We used mouse monoclonal antibodies against: the flag epitope (M2), $\beta$-actin (AC-15), and acetylated tubulin (T7451) (Sigma-Aldrich); the transferrin receptor (136800, Zymed, now Thermo Scientific); postsynaptic density (PSD) 95 (MA1-046, Thermo Scientific); Rac1 (clone 23A8, Millipore); N-cadherin and NR1 (610920, 556308, BD Biosciences); c-myc (9E10, Santa Cruz Biotechnology); ankyrin G (University of California Davis/NeuroMAb mouse monoclonal antibody resource); and neurofascin (gift of M. Rasband, Baylor College of Medicine). We used rabbit polyclonal antibodies against: Par3 and GluR1 (07-330, AB1504, Millipore); VGLUT1 (135-303, Synaptic Systems); PAK (\#2604, Cell Signaling); and Tiam1 and PKC $\zeta$ (C-16, C-20, Santa Cruz Biotechnology). We used a chicken polyclonal against MAP2 (EnCor). Texas Red-labeled phalloidin was obtained from Invitrogen. For secondary antibodies, we used goat polyclonal antibodies labeled with HRP for Western blotting and with Cy3, Cy5, or AlexaFluor-647 from Jackson ImmunoResearch Laboratories. For direct visualization of primary antibodies, we labeled them with the DyLight 650 NHS Ester kit (Thermo Scientific).

DNA reagents. Human BAI1 was obtained from Y. Nakamura (University of Tokyo) and subcloned into pcDNA3. Human Tiam1 subcloned into pCMV-flag was previously described (Tolias et al., 2005). Human 
Par3 was obtained from I. Macara via AddGene (plasmid 19388) and subcloned into pCMVmyc. BAI1 $\cdot$ RKR $\rightarrow$ AAA (Park et al., 2007) was a gift from K. Ravichandran (University of Virginia). pCMV-myc-PAK was the same as used previously (Shamah et al., 2001). We made BAI1 $-\Delta$ TEV using standard molecular cloning techniques. RaichuEV-Racl (Komatsu et al., 2011) was a gift from M. Matsuda (Kyoto University). shRNAs against Par3 (Zhang and Macara, 2006) were a gift from Ian Macara (University of Virginia). shRNAs against BAI1 were designed using the Bioinformatics and Research Computing siRNA Resource at the Whitehead Institute for Biomedical Research and subcloned into pSuper. After screening many shRNAs for effectiveness in knocking down BAIl and maintaining neuronal health, we used the following sequences: 5'-CCCGGACCCTCGTCGTTAC-3' and 5'-GCCCAAATACAGCATCAACA-3'. Experiments shown in Figures 2 and 3 were performed with both of these shRNAs, which yielded the same results; the results of only one are shown in these figures. All constructs were sequence verified.

Cells. Hippocampal neurons were cultured from E19 Long-Evans rats as described previously (Tolias et al., 2005). Neurons were plated in 24-well plates at 70,000125,000 cells per well onto nitric acidwashed glass coverslips coated with $20 \mu \mathrm{g} / \mathrm{ml}$ poly-D-lysine and $3 \mu \mathrm{g} / \mathrm{ml}$ laminin and grown in Neurobasal medium supplemented with B27 (Invitrogen), 2 mm glutamine, and $100 \mathrm{U} / \mathrm{ml}$ penicillin/streptomycin. HEK 293 T cells and NIH 3T3 fibroblasts were subcultured onto poly-D-lysine-coated glass for immunostaining. Their medium consisted of DMEM supplemented with $10 \% \mathrm{FBS}$ and 100 $\mathrm{U} / \mathrm{ml}$ penicillin/streptomycin.

Transfection. Neurons were typically transfected at 6 DIV using the calcium phosphate method of transfection (Tolias et al., 2005). To achieve late knockdown of BAI1, cells were transfected at 14 DIV. This should lead to BAI1 knockdown by 20 DIV. We added $100 \mu \mathrm{M}$ AP5 during the transfection of these older neurons and removed it upon completion. For experiments requiring high transfection efficiencies, we used the Neon Transfection System (Invitrogen) on the day of cell isolation according to manufacturer's protocols. Using EGFP expression as a transfection index, we noted a $>50 \%$ efficiency using this method. HEK 293T cells were transfected using calcium phosphate, and NIH 3T3 cells were transfected using Lipofectamine 2000 (Invitrogen).

Biochemistry. Cells were lysed in $50 \mathrm{~mm}$ Tris, pH 7.5, $150 \mathrm{~mm} \mathrm{NaCl}, 1$ mM EDTA, 5\% glycerol, and 1\% NP-40 freshly supplemented with $1 \mathrm{~mm}$ DTT, Complete protease inhibitor mixture (Roche), $10 \mathrm{~mm} \mathrm{NaF}, 1 \mathrm{~mm}$ $\mathrm{NaVO}_{3}$, and $10 \mathrm{~mm} \beta$-glycerophosphate. For immunoprecipitations, we used standard protocols, pulling down antibody-antigen complexes from postnuclear supernatants with Protein A-agarose using nonimmune serum as a control and washing $4 \times$ with lysis buffer. Standard SDS-PAGE and wet transfer techniques were used to create blots on Immobilon-P (Millipore). Western blots were visualized on film or on an ImageQuant LAS4000 (GE Lifesciences). PSD preparations were performed on P18 rats as previously described (Tolias et al., 2005).

Two-hybrid screen. A yeast two-hybrid screen was performed as described previously (Golemis et al., 2011). The Tiam1 PDZ domain (amino acids 840-1025) in pEG202 was used as bait to screen an E14 rat spinal cord/dorsal root ganglia library.
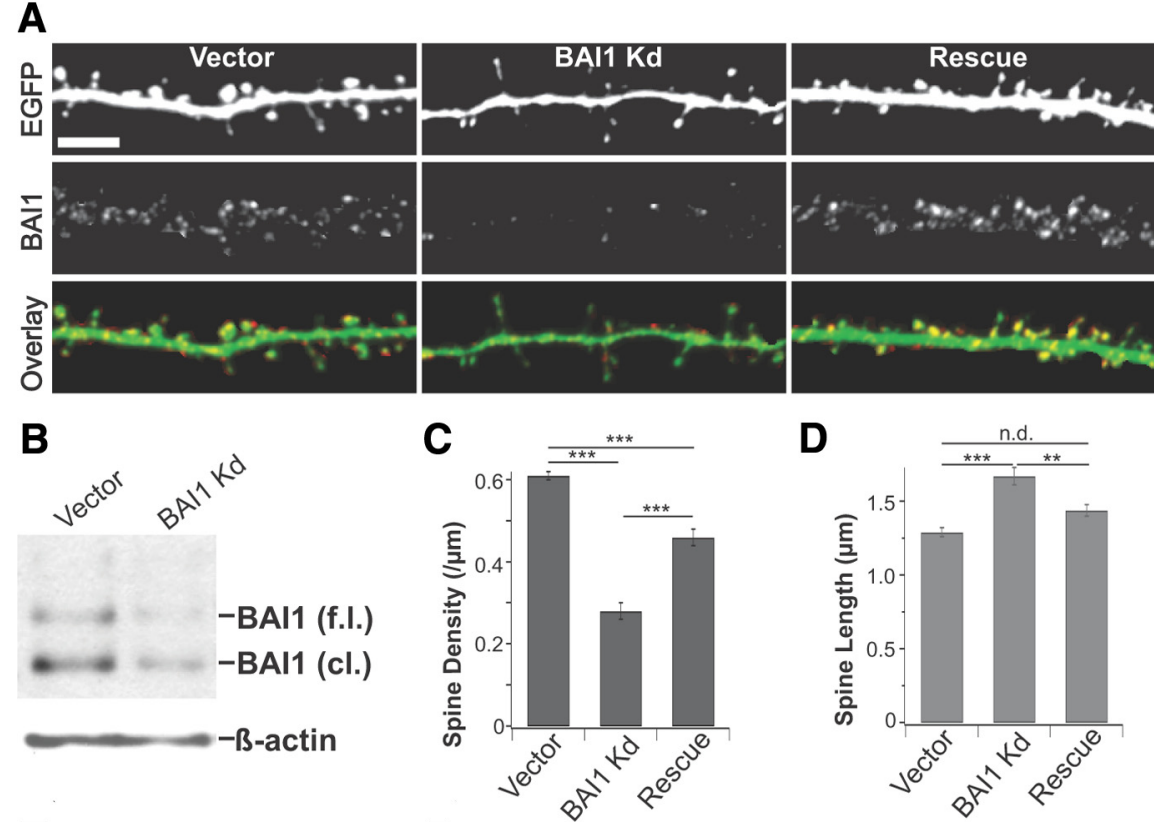

$\mathbf{F}$

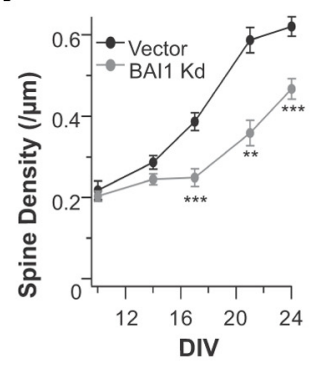

Figure 2. BAl1 is required for spinogenesis in hippocampal neurons. $A$, EGFP and pSuper vector (Vector), shRNA against BAI1 , or shRNA and shRNA-resistant BAI1 (Rescue) were introduced into rat hippocampal neurons at 6 DIV, and the neurons processed for SDS-PAGE. Shown are BAI1 and $\beta$-actin (loading control) blots; $>50 \%$ of the neurons were transfected by this

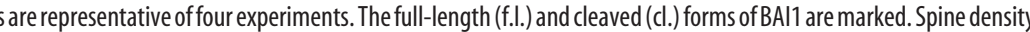
ength $(\boldsymbol{D})$, and filopodial density $(\boldsymbol{E})$ for morphological experiments represented in $\boldsymbol{A}$ are shown $(n=120, N=12)$. $\boldsymbol{F}$ Spine density in rat hippocampal neurons transfected at 6 DIV and fixed on the days indicated on the $x$-axis is shown $(n=40, N=$ 4). Data are mean \pm SEM. ${ }^{* *} 0.01>p>0.001 .{ }^{* * *} p<0.001$. n.d., not different.

Electrophysiology. Whole-cell voltage-clamp recordings were performed with an Axopatch 200B amplifier controlled by Clampex 10 at $25^{\circ} \mathrm{C}$. Data were acquired at $10 \mathrm{kHz}$ and low-pass filtered at $2 \mathrm{kHz}$ with the membrane potential clamped at $-60 \mathrm{mV}$. Series resistance was left uncompensated, and only cells with series resistance $<12 \mathrm{M} \Omega$ were recorded. Whole-cell parameters were monitored every $45 \mathrm{~s}$ to ensure stability, and only data from cells with a steady holding current in the range of 0 to $-80 \mathrm{pA}$ were analyzed. The patch pipette solution contained the following: $115 \mathrm{~mm}$ Cs methanesulfonate, $20 \mathrm{~mm} \mathrm{CsCl}, 10 \mathrm{~mm}$ HEPES, 4 mм ATP-Mg, 0.4 mм GTP-Na, 2 mм $\mathrm{MgCl}_{2}$, 1 mм EGTA, 10 mм phosphocreatine, $50 \mathrm{U} / \mathrm{ml}$ phosphocreatine kinase $(300 \mathrm{mOsm}, \mathrm{pH} 7.4)$. The external perfusion solution contained $140 \mathrm{~mm} \mathrm{NaCl}, 2.4 \mathrm{~mm} \mathrm{KCl}, 10 \mathrm{~mm}$ HEPES, $10 \mathrm{~mm}$ glucose, $2 \mathrm{~mm} \mathrm{CaCl}, 2 \mathrm{~mm} \mathrm{MgCl}_{2}, 0.5 \mu \mathrm{M}$ TTX, and 100 $\mu \mathrm{M}$ picrotoxin (300 mOsm, $\mathrm{pH}$ 7.4). mEPSCs were detected off-line using Axograph X software (AxoGraph Scientific).

Immunocytochemisty and microscopy. Cells were fixed with $4 \%$ formaldehyde/4\% sucrose solution and washed with PBS. Generally, antibodies were applied in PBS containing 5\% goat serum, 2\% BSA, and $0.1 \%$ Triton X-100. Antibodies against PSD95 and Par3 were applied in PBS containing $0.24 \%$ gelatin and $0.72 \%$ Triton X-100. Cells were mounted using aqueous mounting solutions. Confocal images and $z$-stacks were collected on a Leica TCS SP2 confocal microscope with a $63 \times$ oil- 
A
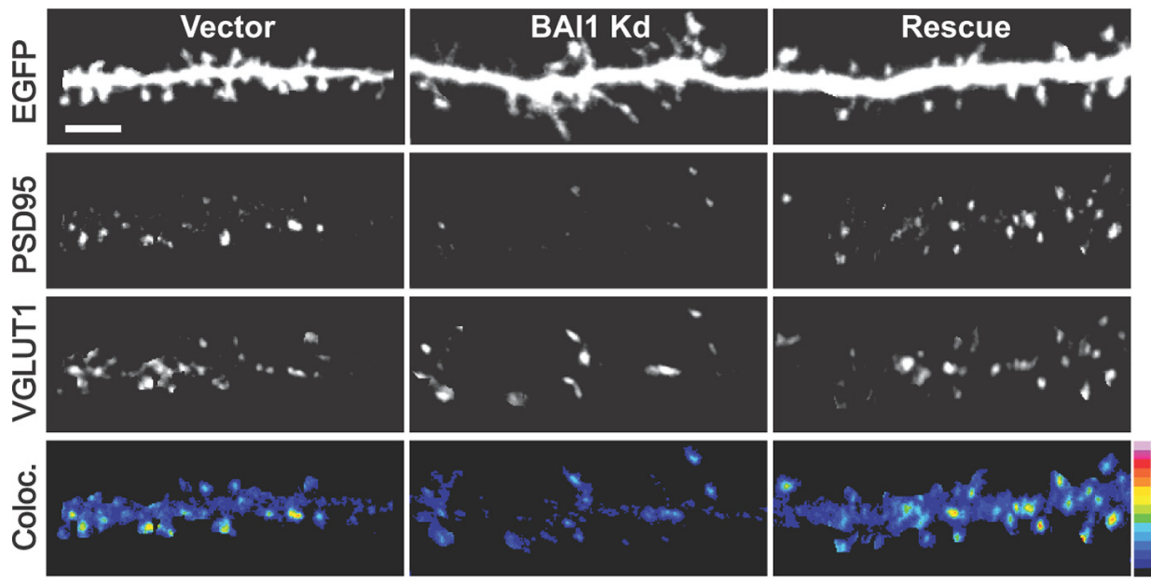

B

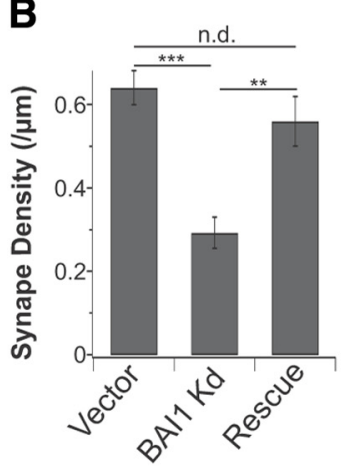

D

C vector

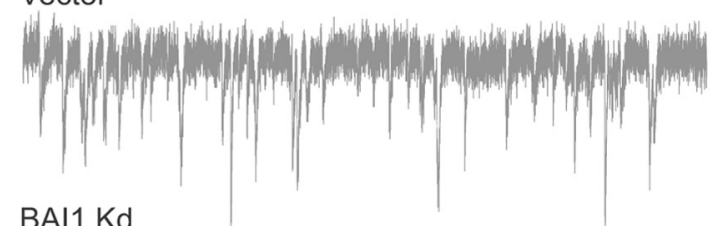

BAl1 Kd
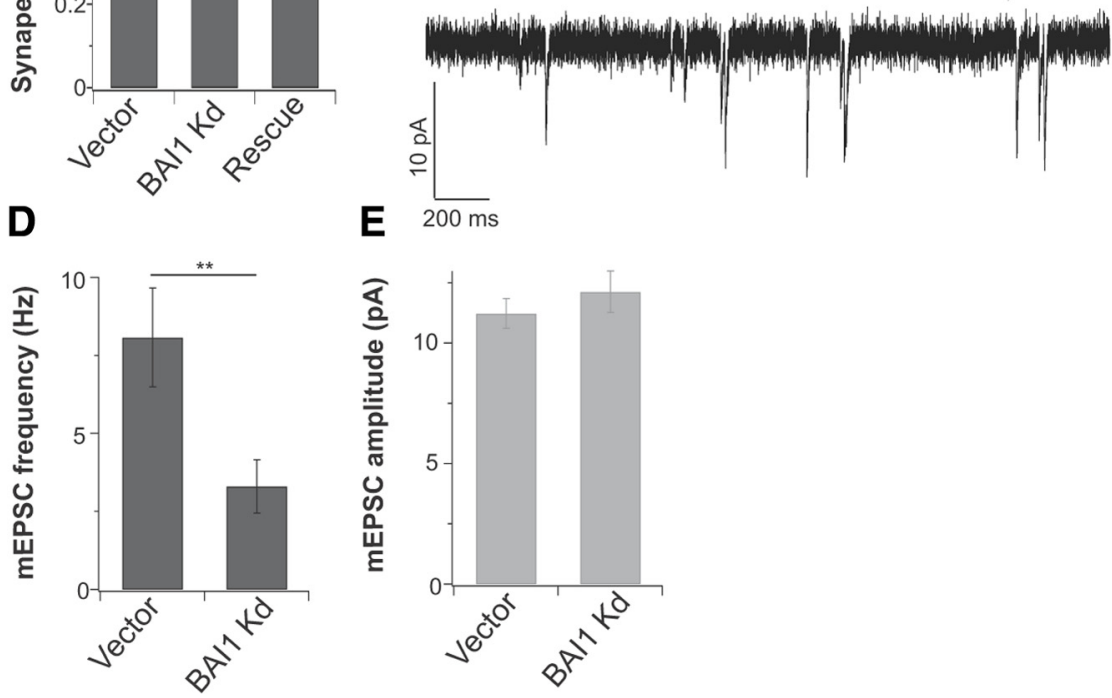

E $200 \mathrm{~ms}$

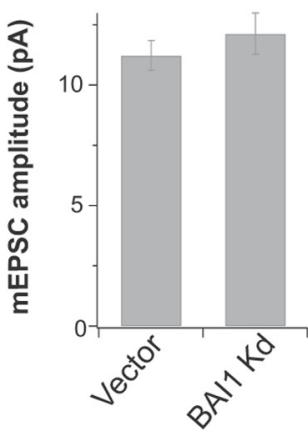

Figure 3. BAl1 is required for excitatory synaptogenesis in hippocampal neurons. $A$, Rat hippocampal neurons transfected on DIV 6 under the same conditions described in Figure $2 A$ were stained for the presynaptic marker VGLUT1 and the postsynaptic marker PSD95. Colocalization panels on the bottom show the strength of colocalization according to the color code at the bottom right; synapses are indicated by regions of high colocalization. Images are representative for 40 neurons $(N=4)$. $B$, Density of these morphological synapses is also shown. $C$, Representative traces of mEPSCs from vector-expressing and BAI1 knockdown neurons at 21 DIV. Traces are representative of 10 neurons $(N=3)$, and mEPSC frequency $(\boldsymbol{D})$ and amplitude $(\boldsymbol{E})$ are shown as well. Data are mean \pm SEM. ${ }^{* *} 0.01>p>0.001 .{ }^{* * *} p<0.001$. n.d., not different.

immersion objective. In neurons, we took $z$-stacks at $0.4 \mu \mathrm{m}$ intervals; and for tissue culture cells, we collected single confocal images where the cells made contact with the coverslip. Images were scrambled and blinded before collection and not revealed until after analysis. All neurons were collected with only the EGFP channel visible to the experimenter. Collection parameters were stable over the course of an experiment, allowing the data to be semiquantitative (i.e., quantitative but uncalibrated). In rescue experiments, neurons not expressing the rescue construct or with net overexpression were collected because of the blinded experimental conditions. Such cells were removed from data pool, and the samples were reblinded and imaged. Unless otherwise noted, we transfected cells with EGFP, which filled the cells, and used the EGFP channel as a mask to restrict data from other channels to the cell of interest.
In utero electroporation and in vivo experiments. In utero electroporation was performed as described previously (Hedstrom et al., 2007). We introduced shRNA or vector plasmids together with $\mathrm{pCx}$-EGFP (CAG promoter driving EGFP expression) into ICR mice (Charles River) at E14. Pups were born and killed at P21. Brains were dissected and fixed with $4 \%$ PFA at $4^{\circ} \mathrm{C}$ for $1 \mathrm{~h}$ on ice and equilibrated in ice-cold 20\% sucrose (w/v); $30 \mu \mathrm{m}$ coronal sections were cut from the brains and stained in PBS containing $0.3 \%$ Triton X-100 and 5\% BSA. Primary antibodies were applied for 2-3 $\mathrm{d}$ and secondary antibodies for $1 \mathrm{~d}$. Sections were imaged in a Leica confocal microscope as above, but with $0.12 \mu \mathrm{m}$ between $z$-sections.

Live imaging of neurons. To measure spine formation and elimination rates, we transfected rat hippocampal neurons with EGFP and either empty pSuper vector or shRNA against BAI1 at 6 DIV. At 14 DIV, we transferred the cells to artificial CSF containing $119 \mathrm{~mm} \mathrm{NaCl}, 26.2$ $\mathrm{mm} \mathrm{NaHCO}_{3}, 2.5 \mathrm{~mm} \mathrm{KCl}, 1 \mathrm{~mm} \mathrm{NaH} \mathrm{PO}_{4}, 1.3$ $\mathrm{mM} \mathrm{MgCl}_{2}$, and $10 \mathrm{~mm}$ glucose. Cells were imaged at $20 \mathrm{~min}$ intervals at $35^{\circ}$ using a Zeiss epifluorescence microscope. Three or four time points were collected in each experiment. To measure Racl activation in live neurons, we cultured rat hippocampal neurons in phenol-red free Neurobasal medium supplemented as above and transfected on 7 DIV with the RaichuEVRacl probe and either empty pSuper or shRNA against BAI1. At 17 DIV, neurons expressing low to moderate levels of the probe were imaged using a Leica TCS SP2 scanning confocal microscope. Images were collected at $\sim 35^{\circ} \mathrm{C}$ using the following settings: Förster resonance energy transfer (FRET) (excitation $458 \mathrm{~nm}$, emission 530-600 nm), CFP (excitation $458 \mathrm{~nm}$, emission 470-500 nm), and YFP (excitation $514 \mathrm{~nm}$, emission 530-500 nm).

$R G D$ peptide experiments. We designed our RGD-containing peptide to correspond to the sequence of BAIl analogous to the peptide used by Shi and Ethell (2006) to promote integrin-dependent spine remodeling. Thus, the peptide sequence was PRGDVCL (amino acids $230-236$ of the full-length BAI1 precursor). A scrambled peptide (LGDCVPR) served as a control. Rat hippocampal neurons were grown to 21 DIV and then treated with freshly dissolved peptides at a concentration of $500 \mu \mathrm{M}$ for $10 \mathrm{~min}$ or $1 \mathrm{~h}$. At the end of the incubation, neurons were lysed and underwent immunoprecipitation as above.

Data analysis. All measurements of spines were obtained from 3D confocal stacks using Imaris software (Bitplane Scientific Software). Spines were visualized by expressing EGFP in neurons to allow unambiguous morphological measurements and were classified as protrustions emanating from dendrites with a clear head structure. Protrusions lacking heads were classified as filopodia. Spine and synapse data were collected from secondary and tertiary segments of dendrite (100-250 $\mu \mathrm{m}$ dendrite analyzed/neuron) using the Imaris filament tool. The Imaris Colocalization Plugin was used to determine Pearson's correlation coefficients and to detect morphological synapses defined by overlap of PSD95 and VGLUT1. We considered Pearson's coefficients $<0.30$ to be chance correlation (Hinkle et al., 1988). We performed discontinuous localization analyses by resolving the staining pattern of each label in our 3D volume into clusters with the 
Imaris Spots tool and using the same tool to identify clusters in each channel that shared $>50 \%$ overlap with clusters in the other channel. Gradients of staining for a marker within a neuron were generated by determining the average intensity value of that marker in spine heads (using Imaris Spots) and the average intensity value of that marker in secondary dendrites or somata (using the Imaris Surfaces) and then subtracting the dendrite or somata value from the spine value. In some cases, the data were normalized by dividing the differences by the dendrite values. All intensity values were obtained directly from 3D stacks; no data manipulations were performed outside of background correction.

Pixel-by-pixel FRET was calculated using the PixFRET plugin (Feige et al., 2005) for NIH ImageJ. ImageJ was also used to quantify data from Western blots and to measure the length of axon initial segment (AIS) and other simple structures from maximum projections of neuronal stacks and single confocal images of tissue culture cells. We also used ImageJ to analyze projection formation and elimination rates in live neurons. Over the time course measured, all formation and elimination events were tabulated, and the data from each cell were normalized for length of dendrite analyzed and total time of measurement. Data are presented normalized to the average of the vector control for that day.

Data were plotted using Igor Pro (WaveMetrics).

Statistics. Data are mean \pm SEM. We used KaleidaGraph (Synergy Software), Igor Pro, and Microsoft Excel to perform statistical analyses. All of our datasets contained normal data. Statistical significance was determined using Student's $t$ test when comparing two independent groups and ANOVA with Tukey's post hoc test when comparing multiple groups. Differences were considered significant when $p<0.05$. The following code was used to denote the strength of statistical differences: ${ }^{\star} 0.05>p>0.01 ;{ }^{* *} 0.01>p>0.001$; and ${ }^{* * *} p<0.001$. Data pairs within a single graph may be assumed to be statistically the same unless otherwise noted. Some nondifferent pairs (n.d.) have been so labeled for emphasis. In figure legends, $n$ refers to the number of subjects of a trial and $N$ refers to the number of independent preparations used to obtain a result.

\section{Results}

\section{BAI1 localizes to excitatory synapses and is necessary} for synaptogenesis

BAI1 exhibits a domain structure typical of A-GPCRs: a long extracellular $\mathrm{N}$-terminal segment with adhesion domains and motifs, followed by a GPS site, which links this segment to the GPCR moiety. BAI1 also has an extended intracellular C-terminal domain that contains cell-signaling motifs (Fig. 1A). BAI1 was discovered in the brain (Nishimori et al., 1997), and its message is enriched in the hippocampus and cortex (Fig. 1C). We posited that BAI1 might be synaptogenic because of its presence in dendritic spines, apparent even in a low-magnification image of a mature hippocampal neuron (Fig. 1B). Comparing the gradient of BAIl staining from spine heads to immediately adjacent segments of dendritic shaft revealed that BAI1 was enriched in spine heads to an extent similar to PSD95, whereas acetylated tubulin was enriched in dendritic shafts and EGFP filled both regions equally (Fig. 1D). Strikingly, even overexpressed BAI1 targeted strongly to spines (Fig. $1 E$ ).

To verify a synaptic localization for BAI1, we used a twofold approach. First, we biochemically purified synapses and found that BAI1 was enriched in the PSD fraction, although to a lower extent than PSD95 (Fig. $1 F$ ). Second, we stained mature cultured neurons for BAI1 and the synaptic markers PSD95 or GluR1 (Fig. $1 G)$. In both cases, BAI1 colocalized significantly with these markers in spines, indicative of synaptic localization. Neuronwide quantitative analysis of colocalization via Pearson's analysis revealed that BAI1 had significant overlap (Pearson coefficients $\left.\left(R_{\mathrm{P}}\right)>0.3\right)$ with both of these markers $\left(R_{\mathrm{p}}=0.398 \pm 0.007\right.$ for PSD95 and $0.438 \pm 0.007$ for GluR1; $n=30$ neurons from 3 preparations). We achieved similar results with the synaptic
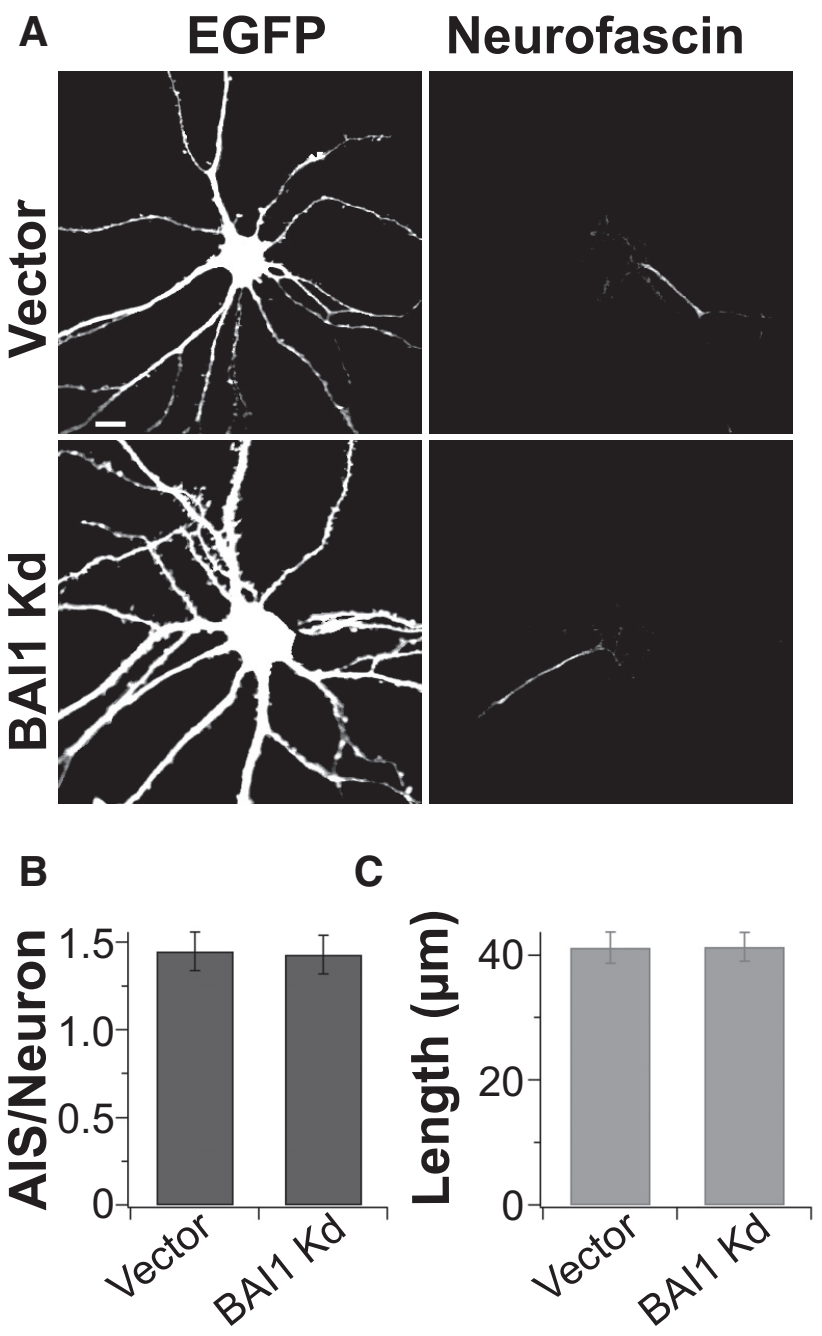

Figure 4. BAI1 knockdown does not affect the AIS. $\boldsymbol{A}$, Neurons transfected with EGFP and vector control or shRNA against BAI1 on DIV 6 were fixed on DIV 21 and stained for the AIS marker neurofascin. Neurofascin staining was used to count the number of AIS per cell $(\boldsymbol{B})$ and AIS length (C). Data are mean \pm SEM $(n=40, N=4)$.

markers NR1 and filamentous actin (F-actin) $\left(R_{\mathrm{P}}=0.485 \pm\right.$ 0.011 and $0.524 \pm 0.006$, respectively). BAI1 also overlapped with $\mathrm{N}$-cadherin and Tiam1, which are both synaptic and perisynaptic $\left(R_{\mathrm{P}}=0.469 \pm 0.010\right.$ and $0.453 \pm 0.012$, respectively) but did not significantly colocalize with the axon initial segment marker ankyrin $\mathrm{G}\left(R_{\mathrm{P}}=0.200 \pm 0.010\right)$. Consistent with these results, discontinuous colocalization analysis indicated that $87.9 \pm 1.1 \%$ of PSD95 clusters and $73.4 \pm 1.1 \%$ of NR1 clusters colocalized with BAI1 $(n=30, N=3)$, once again indicative of a synaptic localization for BAI1. Although the majority of BAI1 was found at synapses $(74.7 \pm 1.1 \%$ of BAIl clusters in spine heads, colocalized with PSD95; $n=30, N=3$ ), it was not exclusively present at synapses because one-fourth of the BAIl clusters were visible in the dendritic shaft (Fig. $1 B$ ), colocalized with acetylated tubulin and the transferrin receptor (data not shown).

To determine whether BAIl is required for synaptogenesis, we developed two nonoverlapping shRNAs against BAIl and used them to knockdown BAIl expression in cultured hippocampal neurons (Fig. 2A,B; see Materials and Methods). BAI1 knockdown resulted in a $50 \%$ reduction in spine density that was rescued by wild-type BAI1 (Fig. 2A,C). Spines in BAI1 knockdown neurons were longer (less mature) than those in control neurons 
A
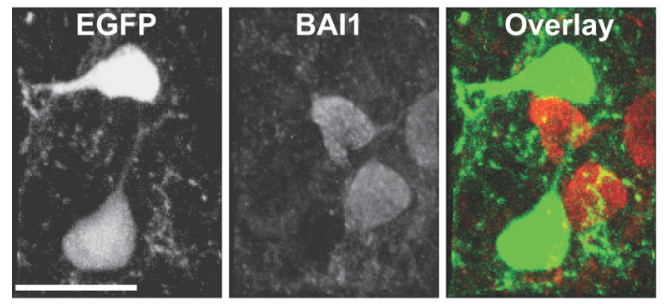

C
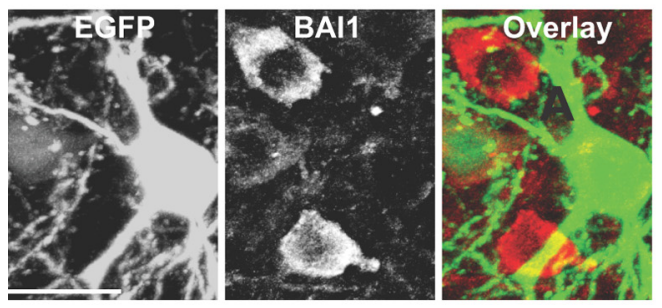

$F$
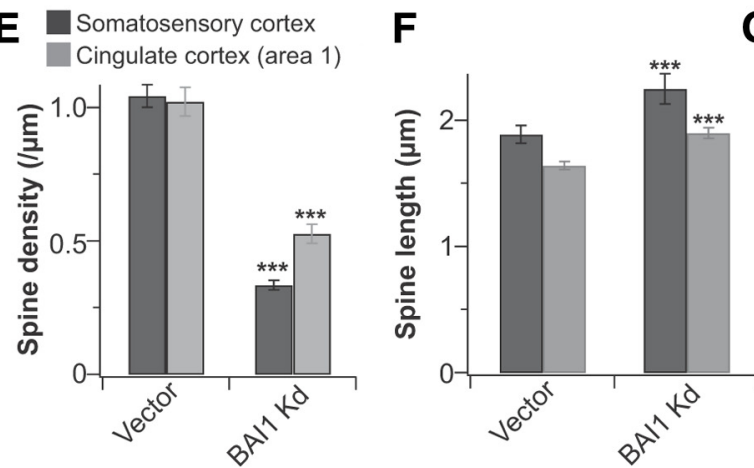

G

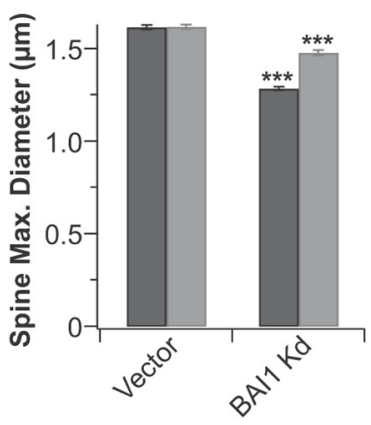

Figure 5. BAl1 is required for spinogenesis in vivo. $A$, Shown is a representative region of somatosensory cortex from a $P 21$ mouse having undergone in utero transfection of shRNA against BAI1 and EGFP on E14. The transfected neurons (green) show no BAl1 staining at this time. All five of the cell somata visible are completely contained within the volume of the confocal stack used to collect these data. Scale bar, $20 \mu \mathrm{m}$. $\boldsymbol{B}$, Enlarged images of secondary dendrites from mice treated as in $\boldsymbol{A}$. Scale bar, $5 \mu \mathrm{m}$. $\boldsymbol{C}, \boldsymbol{D}$, The same types of images are shown for a region of cingulate cortex (area 1). As above, all four somata shown in $C$ are completely contained in the volume of the confocal stack. Images such as these were used to quantify spine density $(\boldsymbol{E})$, spine length $(\boldsymbol{F})$, and spine maximum diameter $(\boldsymbol{G})$ in both of these regions. All data were collected from three pairs (vector and BAl1 Kd) of mice. Spine density data were collected from at least 23 dendritic segments (minimum length $30 \mu \mathrm{m}$ ) from each mouse. Spines in these segments were used for quantification of length and diameter parameters. $n=1348$ for control spines and $n=454$ for BAl 1 knockdown spines in somatosensory cortex, and $n=1098$ for control spines and $n=659$ for BAl 1 knockdown spines in cingulate cortex (area 1). Data are mean \pm SEM. ${ }^{* * *} p<0.001$ versus vector.

(Fig. $2 A, D$ ) and dendritic filopodial density increased by $100 \%$ (Fig. 2A,E), with both phenotypes being rescued by wild-type BAI1 (Fig. 2A,D,E). Our protocol for BAI1 knockdown resulted in a strong reduction in BAI1 expression starting at 14 DIV (data not shown). Interestingly, BAI1 loss affected spine density very soon after the time of BAI1 knockdown (Fig. 2F). We also examined synapses directly using immunostaining and electrophysiology. BAI1 knockdown caused a 50\% loss in excitatory synapses as assessed by colocalization of the presynaptic marker VGLUT1 and the postsynaptic marker PSD95 (Fig. $3 A, B$ ). Indeed, overall levels of PSD95 in the BAI1 knockdown neurons decreased, although the gradient of PSD95 from spines to dendrites was unchanged $(1.58 \pm 0.2$ in control cells and $1.61 \pm 0.2$ in BAI1 knockdown neurons; $n=40$ per condition, $N=4)$. This loss of synapses was rescued by wild-type BAI1 (Fig. $3 A, B$ ). We tested to determine whether manipulating neuronal activity could mimic the effect of BAI1 knockdown on PSD95. However, long-term partial suppression of activity had no effect on PSD95 staining (data not shown). Electrophysiological mea- surement also revealed a $\sim 60 \%$ decrease in mEPSC frequency in neurons with reduced BAIl expression (Fig. $3 C, D)$, whereas $\mathrm{mEPSC}$ amplitude was unchanged (Fig. 3C,E). Finally, BAI1 knockdown spared AIS length and number (Fig. 4), indicating some level of specificity in the actions of BAIl because it is not involved in AIS development and/or maintenance. Our studies of cultured neurons therefore reveal a strong, early requirement for BAI1 in the processes of spinogenesis and synaptogenesis.

To investigate BAIl function in vivo, we electroporated BAIl shRNA into mouse embryos in utero and killed them at postnatal day 21 (P21) to assess their spine morphology. The shRNAs were very effective in vivo, resulting in an almost complete knockdown of BAI1 expression in transfected neurons within both somatosensory cortex (Fig. 5A) and cingulate cortex (area 1) (Fig. 5C). Secondary dendrites imaged in both regions exhibited dramatic decreases in spine density (Fig. $5 B, D, E)$ and small but significant increases in spine length (Fig. $5 B, D, F$ ) and decreases in spine diameter (Fig. $5 B, D, G$ ). These results, combined with the data from cultured neurons, indicate that BAI1 is necessary for spinogenesis in the hippocampus and cortex.

To differentiate between a role in spine formation and spine maintenance, we performed live imaging experiments to directly measure spine formation and elimination rates. Neurons transfected with control or BAI1 shRNAs at 6 DIV were imaged at 20 min intervals on DIV 14 , a time at which exuberant spine formation and remodeling normally take place (Anderson et al., 2004), and BAI1 was effectively knocked down in our experiments (data not shown). We observed a $\sim 40 \%$ decrease in the rate of spine formation in BAIl knockdown neurons (Fig. $6 A, B)$. This implicates BAI1 in the formation of spines. By the time neurons reached maturity (21 DIV), spine formation and elimination rates had dropped to very low levels, and we did not detect significant differences between control and BAI1 knockdown neurons.

Despite our inability to detect increased rates of spine elimination at 14 DIV (Fig. 6C) and 21 DIV (data not shown), we did observe trends toward a higher rate of elimination in BAI1 knockdown neurons. Therefore, we used an alternative means for testing the role of BAI1 in spine stability. Normally, we transfected neurons at 6 DIV to knock down BAIl by 13-14 DIV, ensuring that BAI1 was reduced by the peak period of synaptogenesis. To test for a role in maintenance, we did not introduce BAI1 shRNAs until 14 DIV, resulting in a loss of BAI1 well after the peak phase of spinogenesis. In these late-transfected neurons, we observed small but significant decreases in spine density and 
increases in spine length at 21 DIV (Fig. $6 D-F)$. These data suggest that BAI1 may have a small role in spine maintenance, although the bulk of its action under our conditions appears to be through its effect on spine formation.

\section{BAI1 interacts with and regulates the} localization of components of the cellular polarity machinery

We sought to determine BAI1's mechanism of action in synaptogenesis by identifying its binding partners. A yeast twohybrid screen revealed an interaction between BAI1 and the PDZ domain of Tiam1 (Fig. 7A), suggesting a connection between BAI1 and cellular polarity. We confirmed that BAI1 and Tiam1 interact by demonstrating that exogenously expressed proteins coimmunoprecipitate from tissue culture cells (Fig. 7B) and endogenous proteins coimmunoprecipitate from both hippocampal neurons in culture (Fig. 7C) and adult brain lysates (Fig. 7D). Moreover, immunostaining revealed that BAI1 and Tiam 1 show similar expression patterns throughout the dendritic arbor (Fig. 7E). Because Tiam1 interacts with the Par polarity complex (Mertens et al., 2006; Zhang and Macara, 2006), we next asked whether BAIl could also do so.

Indeed, we observed a weak but detectable interaction between exogenously expressed Par3 and BAI1 in 293T cells (data not shown). Moreover, we found that Par3 and BAI1 coimmunoprecipitate from cultured hippocampal neurons (Fig. $7 F$ ). During development, BAI1 preferentially associates with a short form of Par3, whereas it also interacts with full-length Par3 in mature neurons (Fig. $7 F$ ). BAI1 may interact with Tiam1 and Par3 at synapses because, like BAI1, both Par3 (short and long forms) and Tiam 1 are present in the PSD (Tolias et al., 2005; and data not shown). Because we originally detected an interaction between BAI1 and the PDZ domain of Tiam1, we hypothesized that BAI1 binds to Tiam 1 via its PDZbinding TEV motif. Indeed, BAI1 $\cdot \Delta$ TEV only weakly interacted with Tiam1 (Fig. 7G,H). Because the in vitro interaction between Par3 and BAI1 was difficult to detect reliably, we assessed the effect of BAI1 $\triangle \mathrm{TEV}$ on Par3 interaction by coexpressing BAI1 or BAI1 - $\triangle \mathrm{TEV}$ with myc-Par3 in HEK $293 \mathrm{~T}$ cells and measuring the colocalization between them. BAI1 colocalized with myc-Par3 in these experiments, whereas the coincidence between BAI1 $-\triangle \mathrm{TEV}$ and myc-Par3 was scarcely above chance (Fig. $7 I, J$ ). Thus, BAI1 requires its TEV motif for interacting with both Tiam 1 and Par3.

BAI1 could link to Par3/Tiam1 function in different ways. Because Tiam1-mediated Racl activation is a key output of PAR complex signaling, BAI1 could affect this phenomenon. To test this, we assessed Tiam 1 activity by measuring the Rac1 - GTPmediated autophosphorylation of PAK. We found that, in HEK 293 T cells, PAK autophosphorylates to a similar extent in the presence or absence of BAI1 (Fig. $8 A$ ), suggesting that BAI1 does not directly regulate Tiaml's GEF activity. This result was not entirely unexpected, as several lines of evidence indicate that Tiam 1 is preferentially regulated by changes in its membrane
B
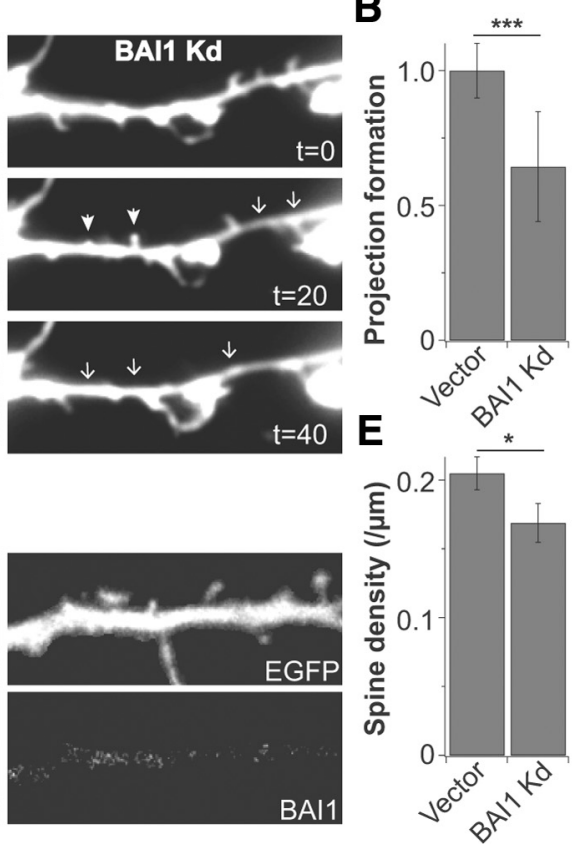

C.

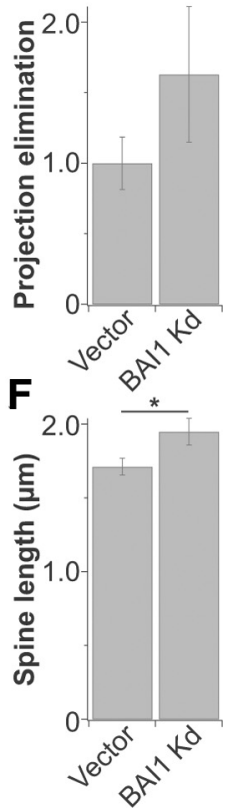

Figure 6. BAl1 reduces projection formation rates during development. $A$, Rat hippocampal neurons were transfected with as these, projection formation $(\boldsymbol{B})$ and projection elimination $(\boldsymbol{C})$ rates were collected $(n=16, N=4)$. $\boldsymbol{D}$, Representative images of experiments in which rat hippocampal neurons were transfected on DIV 14 and fixed and stained on DIV 22 . Spine density $(\boldsymbol{E})$ and length $(\boldsymbol{F})$ were calculated for these experiments $(n=24, N=3) .{ }^{*} 0.05>p>0.01$. ${ }^{* * *} p<0.001$.

association and localization rather than its activity (Mertens et al., 2003). Another possibility is that BAI1 regulates the stability of Tiam 1 and/or Par3. We measured the amounts of Tiam 1 and Par3 present in control and BAI1 knockdown neurons under conditions in which $>50 \%$ of the primary hippocampal expressed the shRNA. These conditions led to robust knockdown of BAI1 (Fig. 2A), but there were no detectable changes in the expression levels of Tiam 1 and Par3 (Fig. $8 B$ ). The interaction between BAI1 and Par3/Tiam1 must therefore serve some purpose outside of directly regulating Par3/Tiam1 activity or stability.

Par3 is a critical determinant of the asymmetric distribution of cell components (Ohno, 2001; Mertens et al., 2006). It is therefore conceivable that either Par3 recruits BAI1 to spines where it functions in parallel with Tiam1 or that BAI1 recruits Par3 to spines, which in turn recruits Tiam1. We tested the first possibility by examining BAI1 localization in neurons lacking Par3. Although Par3 knockdown caused striking changes in dendrite and spine morphology, BAI1 was still strongly concentrated in spines, as shown by the gradient of BAIl from dendrites into spines being even stronger in the knockdowns (Fig. 8C,D). Therefore, we tested the second possibility that BAI1 is required for proper Par3 localization. Loss of BAI1 had a profound effect on Par3 localization in dendrites (Fig. 8E). In control neurons, Par3 was distributed throughout the dendritic arbor in discrete puncta, many of which associated with spines. However, in BAI1 knockdown neurons, the Par3 staining collapsed into a large inclusion in the soma and a few smaller dendritic inclusions proximal to the soma (Fig. 8E). We measured the gradients of Par3 immunoreactivity between the spines and dendrites and between the spines and somata (see Materials and Methods) and determined that Par3 localization shifted away from spines in both cases (Fig. $8 \mathrm{H}, \mathrm{I}$ ). Similarly, when we monitored the distribution of exogenously 

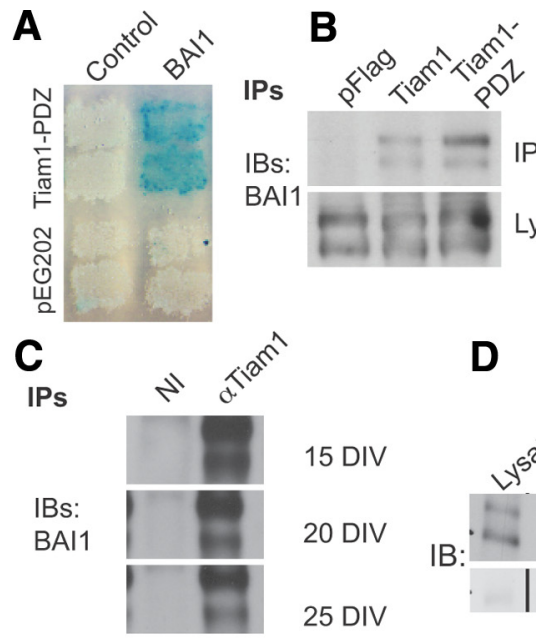

D

15 DIV

20 DIV

25 DIV

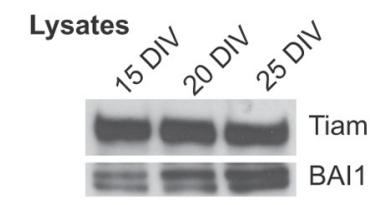

$\mathbf{F}$
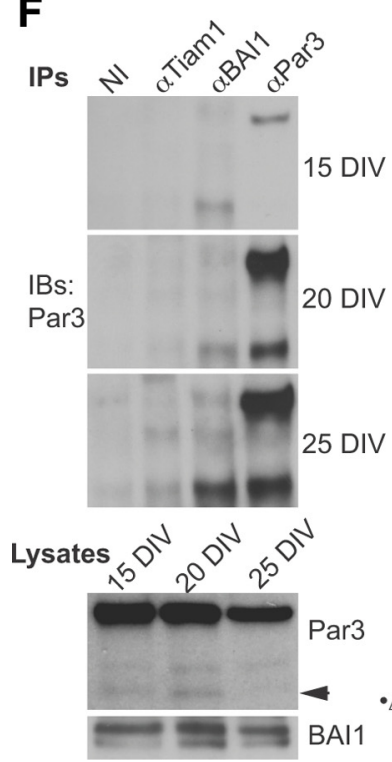

Lysates

H

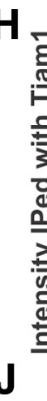

E

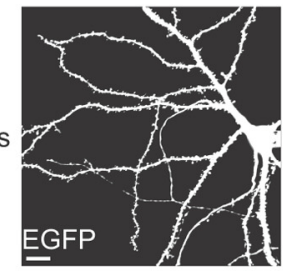

IP:
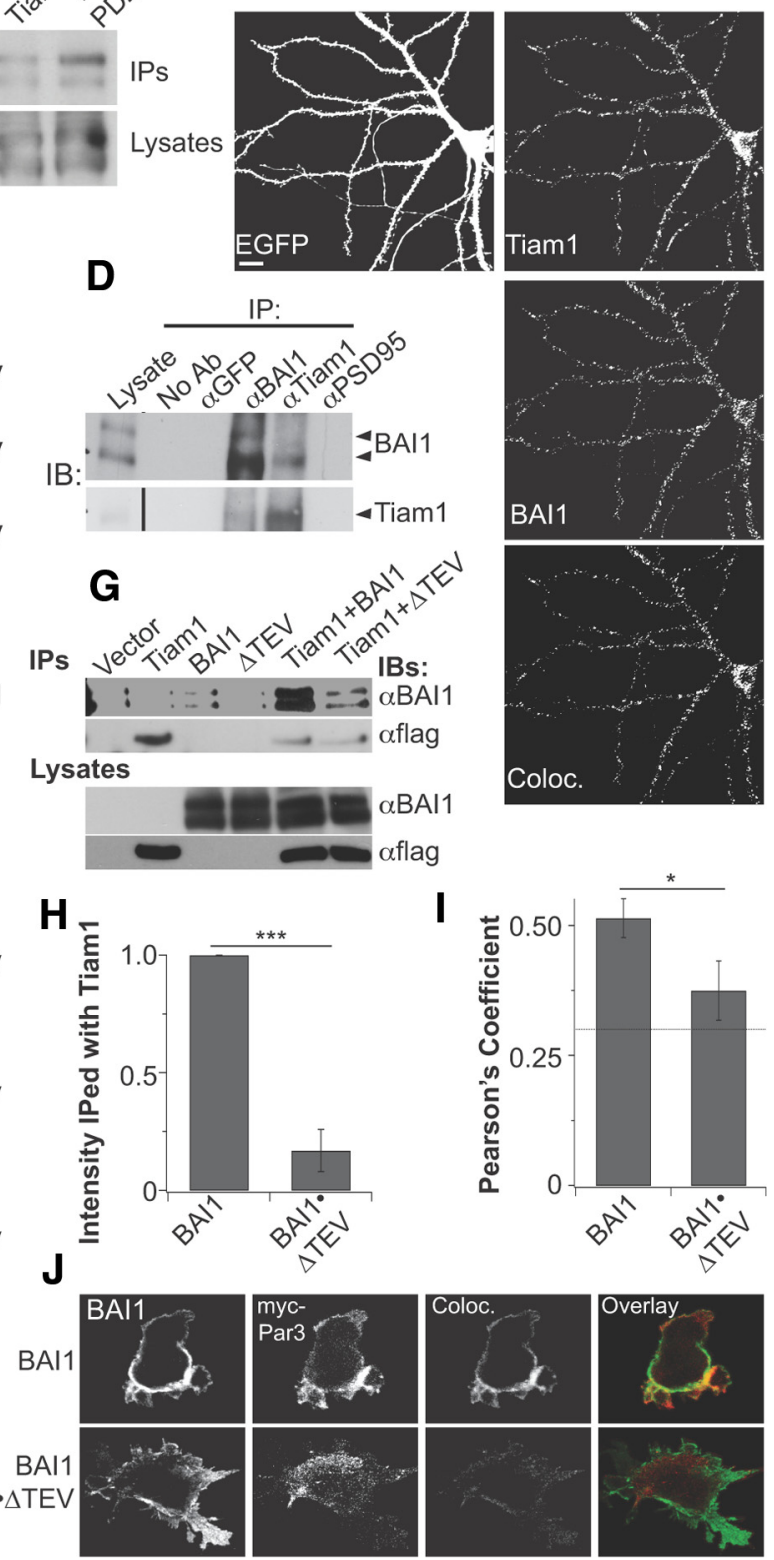

Figure 7. BAl1 interacts with cell polarity machinery. $\boldsymbol{A}$, Shown are results of a two-hybrid screen using an embryonic rat spinal cord library and the Tiam1 PDZ as bait. B, BAl1 and vector, flag-Tiam1, or flag-Tiam1-PDZ were expressed in 293T cells and immunoprecipitated using antiflag antibodies. Shown are blots of lysates and immunoprecipitates probed for BAl1. Images are representative of three independent experiments. C, Rat hippocampal neurons in culture were lysed on the days indicated and immunoprecipitated with nonimmune serum (NI) or antibodies against Tiam1. Shown are blots of immunoprecipitates and lysates representative of eight experiments. $\boldsymbol{D}$, The indicated immunoprecipitations were performed on postnuclear brain lysates collected from adult rat brain. A longer exposure was required to visualize the Tiam1 band in the lysates than the other bands (indicated by the line on the blot). Data are representative of three independent experiments. $\boldsymbol{E}$, The 21 DIV rat hippocampal neurons were stained for Tiam 1 and BAl1. Shown are images representative of 50 neurons from five preparations, as well as an image showing the areas of significant colocalization. $\boldsymbol{F}$, Rat hippocampal neurons in culture were lysed on the days indicated and immunoprecipitated with antibodies against Tiam1, BAI1, or Par3 or NI serum. Lysates and immunoprecipitates shown are representative of eight experiments. Bands at the top and bottom of each panel each are known isoforms of Par3. G, BAI1, BAl1 • $\Delta$ TEV, and flag-Tiam 1 were expressed in the indicated combinations and the cells lysed and immunoprecipitated with antiflag antibodies. Shown are blots of immunoprecipitates and lysates representative of seven experiments. $\boldsymbol{H}$, The intensity of BAl1 staining in the flag immunoprecipitates is quantified $(n=7) . I, J$, myc-Par3 and BAI 1 or BAI1 • $\Delta$ TEV were expressed in HEK $293 \mathrm{~T}$ cells and the cells processed for immunocytochemistry. Pearson's correlation coefficients were calculated for overlap between the two proteins. $I$, The line at 0.3 represents the value above which colocalization is greater than chance. $J$, Representative images $(n=18, N=3)$. Data are mean \pm SEM. ${ }^{*} 0.05>p>0.01 .{ }^{* * *} p<0.001$. expressed Par3 in neurons, we saw a collapse of Par3 into the neuronal somata (Fig. 8F). Exogenous Par3 was distributed in discrete puncta throughout the dendritic arbor of control neurons, but there was a $60 \%$ decrease in the punctal density and a $30 \%$ decrease in punctal diameter in BAI1 knockdowns $(n=30$ neurons from three preparations; $p>0.001$ for density, $p>0.05$ for diameter). Thus, it is BAI1 that is required for the proper localization of Par3.

Because BAI1 knockdown led to loss of Par3 from synaptic sites, we hypothesized that Tiam1 would be lost as well. Indeed, we found that, while Tiam1 was located in puncta throughout dendrites and spines in control neurons, it was lost from these loci in BAI1 knockdown neurons (Fig. $8 G)$. Tiam 1 gradients between spines and dendrites (Fig. $8 H$ ) and between spines and somata (Fig. 8I) shifted away from the spines in these neurons relative to controls. Tiam 1 was also lost from the spines of BAI1 knockdown neurons overexpressing Tiam1 relative to neurons simply overexpressing Tiam1 (data not shown). These data suggest a model in which Tiam 1 is mislocalized, but not lost, throughout neurons lacking BAI1. As we did above for PSD95, we tested whether the effect of BAI1 knockdown could be an indirect effect of BAI1's suppression of neuronal activity. As above, partial suppression of activity did not cause a loss of either Tiam1 or Par3 puncta from dendrites. As Tiam 1 and Par3 are required for proper synaptogenesis in hippocampal neurons (Tolias et al., 2005; Zhang and Macara, 2006; Tolias et al., 2007), these results suggest that BAI1 positively regulates synapse development by providing these proteins proper access to synaptic sites.

We also analyzed the localization of neuronal proteins not interacting with BAI1. PKC $\zeta$ is often associated with Par3 (Ohno, 2001; Mertens et al., 2006). When we analyzed the localization of $\mathrm{PKC} \zeta$ in BAI1 knockdown neurons, we found that it was distributed throughout the dendritic arbors of hippocampal neurons, nearly filling stretches of dendritic shafts. This was very similar to that in control neurons (Fig. $8 \mathrm{~K}$ ), and the gradients between spines and soma (Fig. 8I) were therefore unaffected. Somatodendritic staining patterns of the dendritic proteins MAP2 (dendritic intensity of $1.00 \pm 0.05$ in control neurons, $0.93 \pm 0.04$ in BAI1 knockdown neurons; $n=30$ neurons from 3 preparations, $p>0.05$ ) and acetylated tubulin (dendritic intensity of 
A

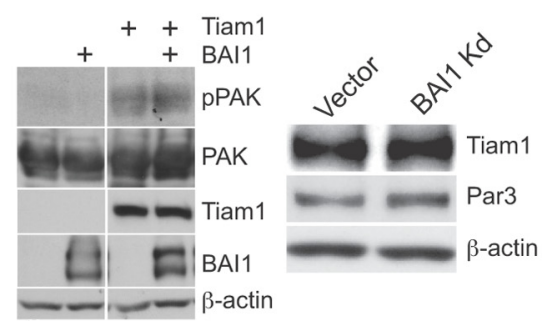

C

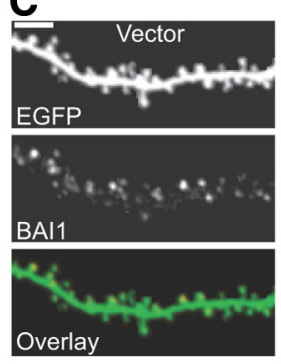

D

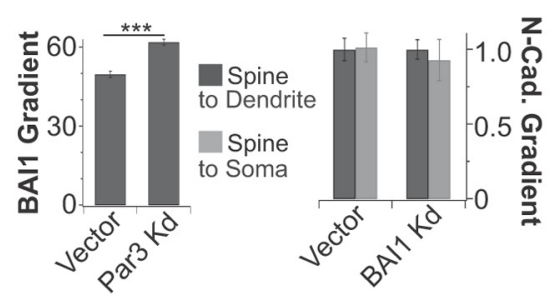

E
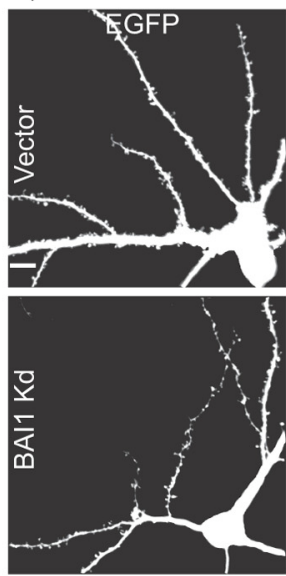

G

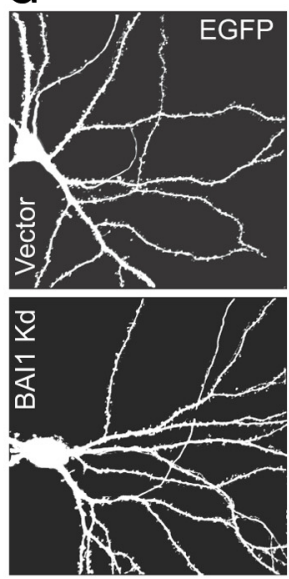

K
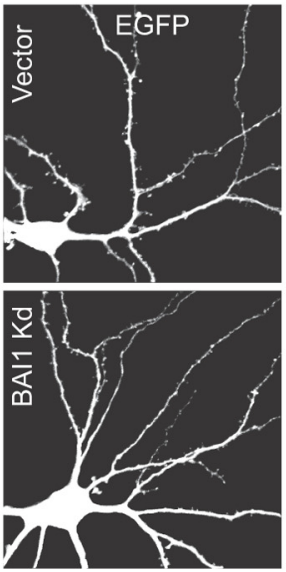
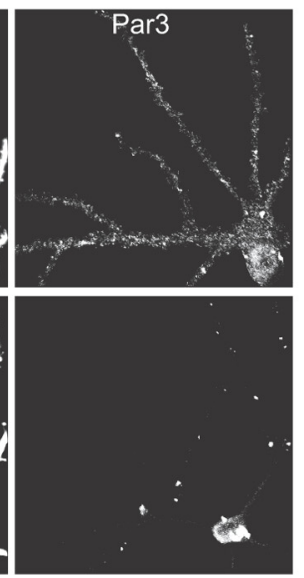

F
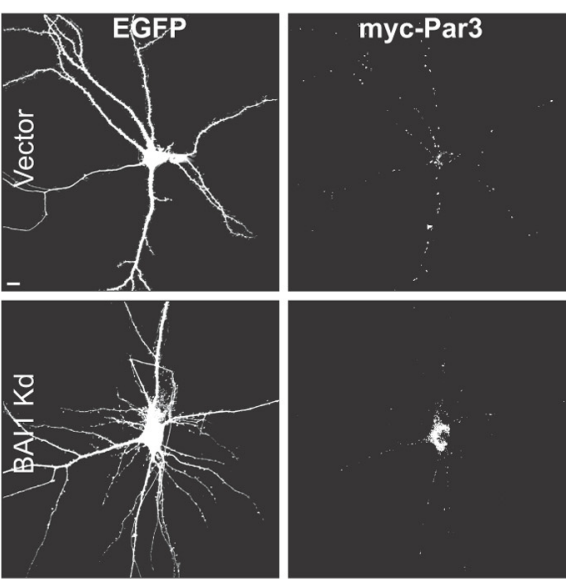

H
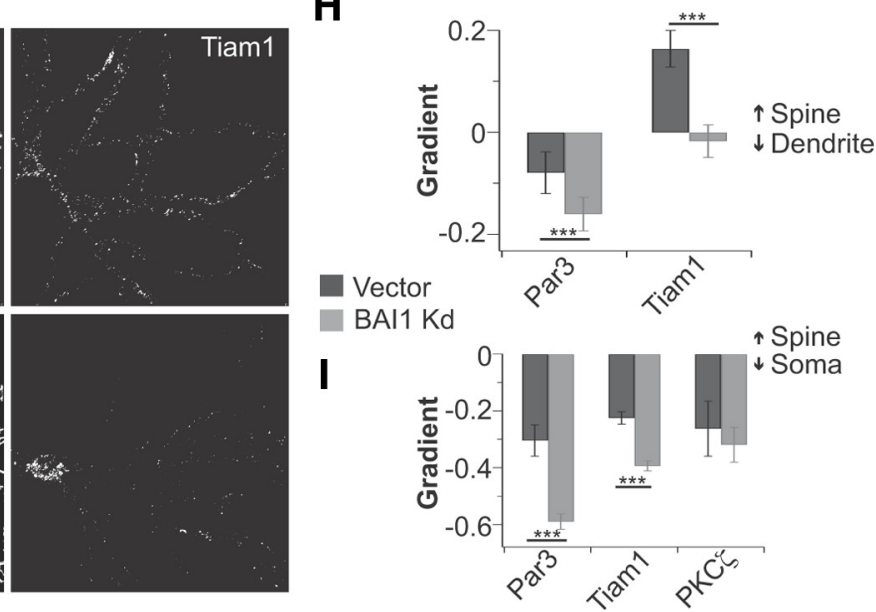

L
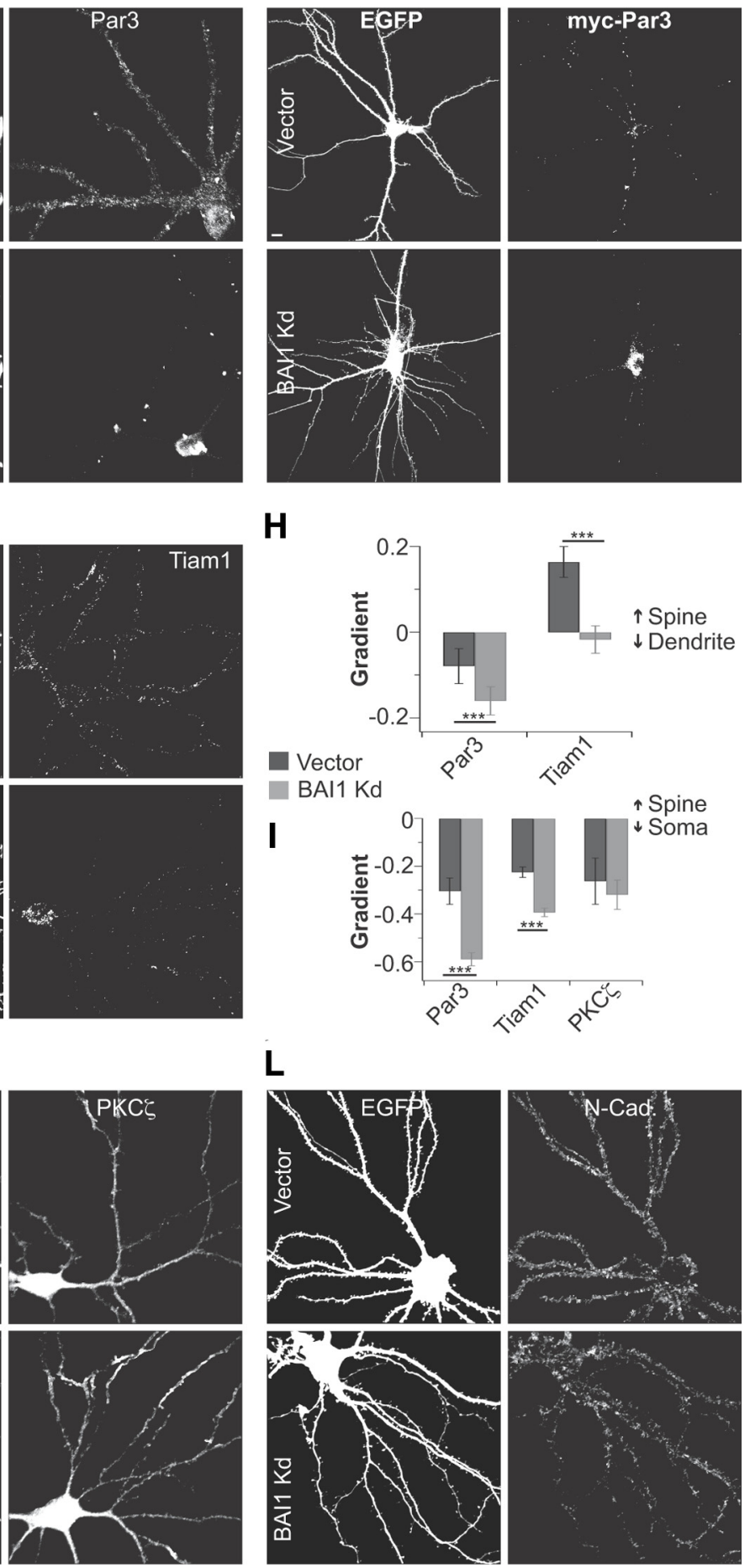

Spine endrite

Figure 8. BAl1 controls the localization of Par3 and Tiam1 in neurons. A, HEK 293T cells were transfected as indicated and Rac1 activation measured indirectly by blotting for phospho-PAK, which autophosphorylates in response to its activation by Rac1 - GTP. PAK and $\beta$-actin serve as loading controls in this experiment. Data are representative of five independent experiments. $\boldsymbol{B}$, Hippocampal neurons transfected with the high-efficiency Neon system were probed for Tiam 1 and Par3 as indicated. The blots shown are for the same preparation as that shown in Figure $2 B$; BAl1 was knocked down by $>50 \%$. Blot is representative of four experiments. C, EGFP and BAl1 were visualized at 21 DIV in rat neurons with or without Par3 knockdown. BAl1 was overexpressed at low levels in this experiment. Scale bar, $5 \mu \mathrm{m}$. $\boldsymbol{D}$, The BAl1 gradient between spines and dendrites for these experiments was quantified $(n=30$ neurons, $N=3)$. EGFP and endogenous $\operatorname{Par} 3(\boldsymbol{E})(n=40 ; N=4)$, exogenous $\operatorname{Par} 3(\boldsymbol{F})(n=30 ; N=3)$, $\operatorname{Tiam} 1(\boldsymbol{G})(n=50 ; N=5), \operatorname{PKC} \zeta(\boldsymbol{K})(n=40, N=4)$, or $\mathrm{N}$-cadherin $(\boldsymbol{L})(n=40, N=4)$ were visualized at 21 DIV in control rat hippocampal neurons or in BAl1 knockdown neurons. $J$, Gradients of N-cadherin between spines and dendrites (black) and spines and somata (gray) were measured in control and BAl1 knockdown neurons. Gradients of Par3, Tiam1, and PKC $\zeta$ from spines to dendrites $(\boldsymbol{H})$ and spines to somata $(\boldsymbol{I})$ are also given. Dataset sizes are given above. Data are shown \pm SEM. ${ }^{* * *} p<0.001$. 
A

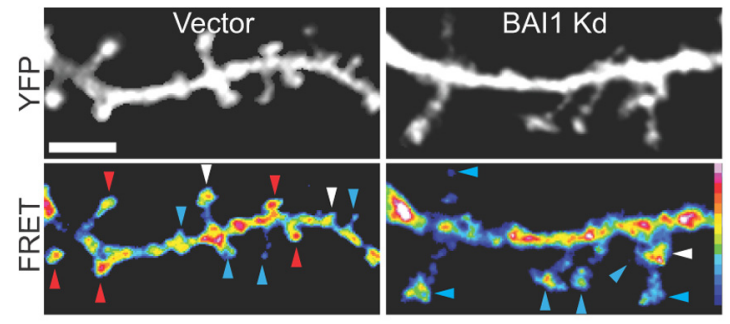

C

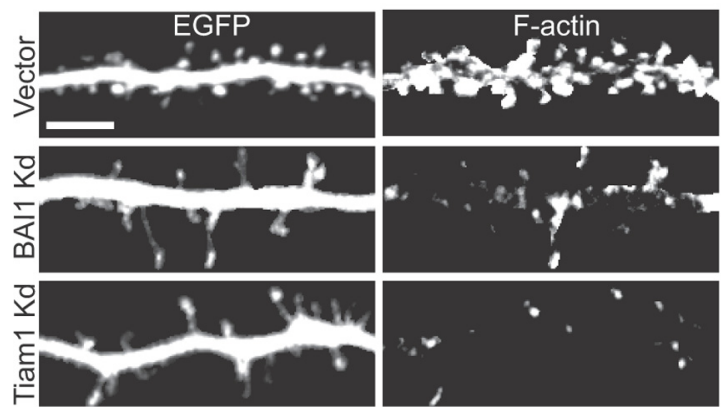

B

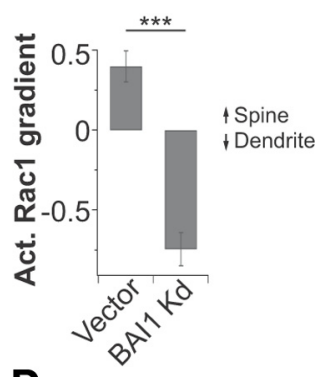

D

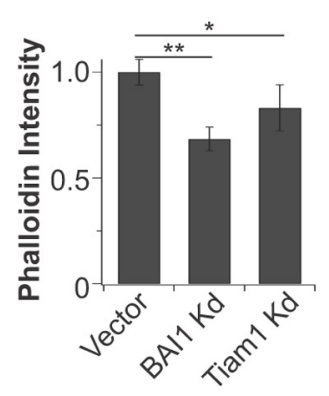

Figure 9. Loss of BAl1 alters Rac1 activation and F-actin in hippocampal neurons. $\boldsymbol{A}$, Rac1 activation was visualized using the improved Raichu-Rac1 FRET-based live cell probe in 17 DIV rat hippocampal neurons. Dendrite structures in secondary dendrites were visualized by exciting the YFP acceptor directly (top), whereas Rac1 activation was assessed by measurement of FRET normalized to the level of the Raichu-Rac1 probe. The color code for Rac1 activation is shown in the bottom right-hand corner of the panel. Arrowheads indicate the direction of the Rac1 activation gradient in individual spines. Red arrowheads indicate higher Rac1 activation in the spine head than the adjacent dendrite (+ gradient); blue arrowheads, lower Rac1 activation in the spine head than in the adjacent dendrite ( - gradient); white arrowheads, equal Rac1 activation in the spine head and adjacent dendrite. $\boldsymbol{B}$ Rac1 activation gradients from $\sim 350$ spines in each condition were pooled and are shown. Data were collected from 30 neurons $(N=3)$. C, F-actin was visualized using Texas Red-phalloidin in fixed 21 DIV rat hippocampal neurons expressing EGFP and vector or shRNAs against BAl1 or Tiam1. D, Phalloidin intensity data from the heads of $\sim 350$ spines in each condition are shown. Data were collected from 30 neurons $(N=3)$. Data are meant $\pm S E M .{ }^{*} 0.05>p>0.01 .{ }^{* *} 0.01>p>0.001 .{ }^{* * *} p<0.001$.

$1.00 \pm 0.08$ in control neurons, $0.90 \pm 0.06$ in BAI1 knockdown neurons; $n=30$ neurons from 3 preparations, $p>0.05$ ) were also unaffected by BAI1 knockdown, suggesting that loss of BAI1 does not alter the basic structure of dendrite shafts. Finally, we examined the distribution of $\mathrm{N}$-cadherin, which is present in dendritic spines. Some perturbation of $\mathrm{N}$-cadherin distribution in BAI1 knockdown neurons was detected because of the lack of spines relative to control neurons (Fig. $8 \mathrm{~L}$ ). Nevertheless, the gradients of $\mathrm{N}$-cadherin between spines and somata and between spines and dendrites (Fig. 8J) were unperturbed, suggesting that $\mathrm{N}$-cadherin had normal access to those spines that did form. These results demonstrate that not all dendritic- and spinelocalized proteins require BAI1 for their proper localization.

\section{BAI1 controls the polarized activation of Rac1 in dendrites via Par3/Tiam 1}

Because the downstream target of Par3/Tiam1, Rac1, positively regulates signaling pathways leading to spinogenesis and synaptogenesis (Ramakers, 2002; Tada and Sheng, 2006; Benarroch, 2007; Tolias et al., 2011), we asked whether the defects associated with BAI1 loss might be explained by perturbations in Rac1 activation. To investigate BAI1-dependent changes in Racl activation, we used the Racl activation reporter RaichuEV-Racl (Komatsu et al., 2011). This reporter is suitable for live-cell imaging and reports Racl activation via an increase in FRET. In wild-type neurons, Racl activation is highest in and around spines (Fig. 9A). Not all spines have elevated Racl, and presumably those spines undergoing enlargement because of synapto- genesis or synaptic strengthening are most marked by elevated Racl activation (Ramakers, 2002; Tada and Sheng, 2006; Benarroch, 2007; Tolias et al., 2011). Loss of BAI1 had profound effects on Racl activation. The locus of highest Racl activation in BAI1 knockdown neurons was shifted into long stretches of the dendritic shaft, and overall Racl activation was higher in the dendritic shaft than in spine heads (Fig. 9A,B). This leads to a reversal of the activated Racl gradient along the spine-shaft axis. One of the most important outcomes of Racl signaling is its effect on the actin cytoskeleton (Tada and Sheng, 2006; Benarroch, 2007). Dendritic spines, in particular, are highly enriched in F-actin (Tada and Sheng, 2006; Bosch and Hayashi, 2012). Loss of BAI1 leads to decreased intensity of F-actin (phalloidin) staining in spine heads comparable with that resulting from loss of Tiam1 (Fig. $9 C, D)$. These data strongly suggest that BAI1 is required for proper Rac1 signaling and F-actin assembly in developing spines.

To confirm that the effects of BAIl knockdown are mediated by loss of synaptic Par3/Tiam1, we rescued BAI1 knockdown neurons with the $\triangle \mathrm{TEV}$ mutant described in Figure 7. Exogenous BAI1 • $\Delta \mathrm{TEV}$ localized to dendritic spines as well as wild-type BAI1 (Fig. 10B), even when overexpressed (Fig. 10A). Compared with wild-type BAI1, the $\triangle$ TEV mutant was ineffective in rescuing the spine density (Fig. $10 \mathrm{~B}, C$ ) and spine length (Fig. $10 B, D$ ) BAI1 knockdown phenotypes. Importantly, BAI1 levels in these experiments were carefully controlled so that, in both rescue conditions, overall BAI1 levels were comparable with those of the wild-type protein (Fig. 10E). We also tested whether the $\triangle T E V$ mutant can rescue the localization of Par3 in neurons. Because our BAI1 and Par3 antibodies were both raised in rabbits, we expressed myc-tagged Par3 in neurons. As in Figure $8 F$, myc-Par3 expressed in neurons was apparent in well-defined clusters throughout the dendritic arbor. These clusters were greatly reduced in BAI1 knockdown neurons (Figs. $8 F$ and $10 F$ ), but readily apparent in knockdown neurons rescued with wildtype BAI1 (Fig. $10 F, G$ ). Importantly, BAI1 $-\Delta$ TEV did not restore the Par3 clusters (Fig. $10 F, G$ ), although the mutant was expressed to comparable levels as the endogenous protein and wild-type rescue (Fig. 10F). Also, myc-Par3 was expressed in the all four conditions, as evidenced by somal staining of the neurons (Fig. $10 F)$. We also confirmed that Par3 knockdown caused defects similar to those caused by BAI1 knockdown (data not shown), including loss of synapses and spines, increases in filopodia, and loss of Tiam1 from spines, as previously reported (Zhang and Macara, 2006).

Our results thus far suggest that BAI1 is required for proper localization of Par3. Because Par3 is required for proper localization of Tiam1, we postulated that increased Tiam1 may compensate for BAI1 loss. Although Tiam1 is required for excitatory synaptogenesis, all but the most mild overexpression of Tiam 1 leads to a phenotype that is reminiscent of Tiam1 loss, namely, the loss of spines and synapses (Zhang and Macara, 2006). There- 
fore, it is also possible that loss of BAIl would correct defects caused by Tiam 1 overexpression by preventing Tiam 1 levels in the dendrite from rising to the point at which Racl activation becomes too high. We tested these hypotheses in the experiments shown in Figure $11 A-C$. By themselves, BAI1 knockdown and Tiam1 overexpression cause qualitatively similar phenotypes: there is a decrease in spine density (Fig. $11 A, B$ ), an increase in spine length (data not shown), and an increase in filopodial density (Fig. $11 \mathrm{~A}, \mathrm{C}$ ). However, these two treatments cancel each other out for each of these phenotypes (Fig. 11A-C; and data not shown). Staining confirmed that the amount of Tiam 1 in the dendritic arbor (and especially in spine heads) decreased in the BAI1 knockdown neurons, increased in the Tiam 1 overexpressing neurons, and recovered when both treatments were performed at once (Fig. 11A). Thus, BAI1 has a role in positioning and restricting Tiam1, and BAI1 loss can be overcome by increasing the levels of Tiam1 in the dendritic arbor.

In professional phagocytes, BAIl activates Rac1 via DOCK180/ELMO1, an atypical Rac1-GEF complex that promotes the cytoskeletal remodeling required for phagocytosis (Park et al., 2007). BAIl interacts with ELMO1 through a coiled-coil region in its C-terminal tail (amino acids 1431-1520), and mutating an RKR motif within this region (amino acids 1489-1491) to AAA disrupts the BAI1-ELMO1 interaction (Park et al., 2007). To determine whether BAI1 regulates Racl via DOCK180/ELMO1 in synaptogenesis, we rescued BAI1 knockdown neurons with this mutant. As was the case for the $\Delta$ TEV mutant, BAI1 $\cdot$ RKR $\rightarrow$ AAA localized to dendritic spines at both rescue (Fig. 11D) and overexpressed (Fig. 10A) levels. BAI1 $\cdot$ RKR $\rightarrow$ AAA rescued both the spine density and spine length parameters to the same extent as wild-type BAI1 (Fig. $11 D-F)$, indicating that DOCK180/ ELMO1 is not required for mediating BAI1's effects on Rac1 signaling in synaptogenesis. These results establish BAI1/ Par3/Tiam1 as the critical module for the control of Racl activation in excitatory synaptogenesis.

\section{Integrin binding regulates the association of BAI1 with Par3/ Tiam1}

BAI1 is a cell surface receptor; thus, we would expect it to respond to extracellular signaling. As noted above, one of several potential ligand-binding domains on BAI1 is its N-terminal RGD motif, which binds to $\alpha_{\mathrm{v}} \beta_{5}$ integrins (Koh et al., 2004). We designed a peptide to mimic the specific RGD motif of BAIl and tested it for its ability to modulate the BAI1/Par3/Tiam1 module. As shown in Figure 12, in as little as 10 min, treatment with the RGD peptide caused a significant increase in the association of both Par3-
C

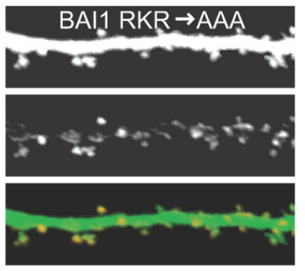

है

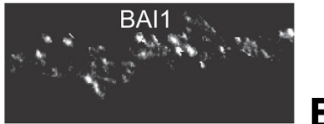

$0-\frac{1}{2}$

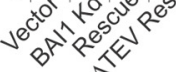

E

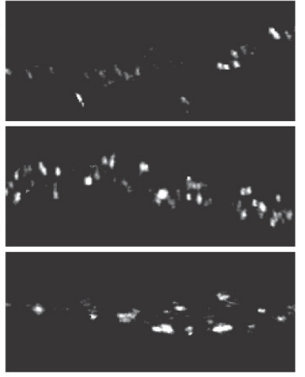

E
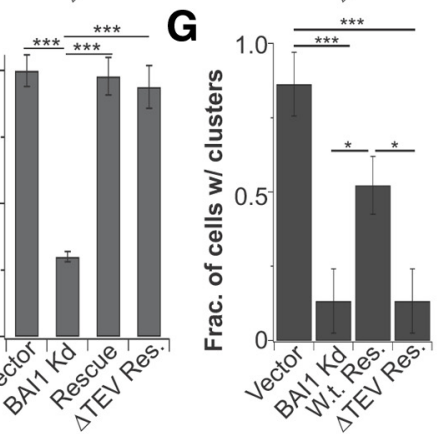

Dendrites
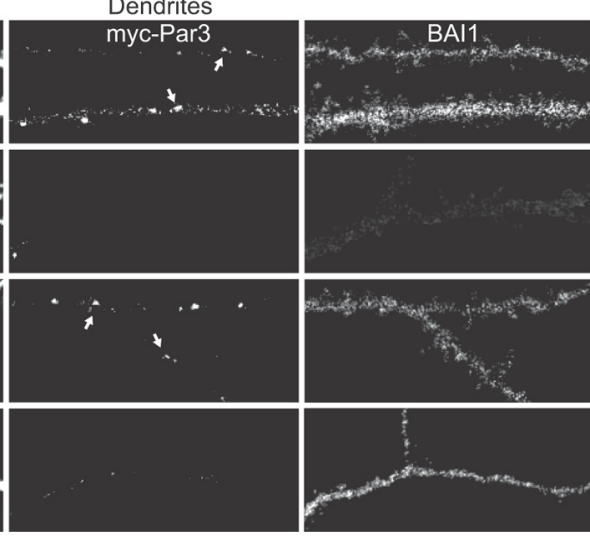

Somata

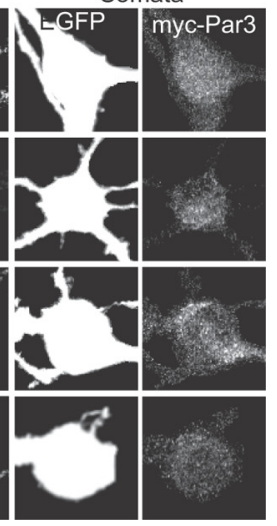

Figure 10. BAl1 interaction with Par3/Tiam 1 is required for spinogenesis and Par3 localization. $A, B A l 1 \cdot \Delta \mathrm{TEV}$ (left) and BAl1 $\bullet$ RKR $\rightarrow$ AAA (right) were introduced along with EGFP in hippocampal neurons at 6 DIV, fixed at 21 DIV, and stained for BAI1. Images are 政 30 neurons $(N=3)$. $B$, Rat hippocampal neurons were transfected on DIV 6 with vector, shRNA against BAl1 (BAl1 Kd), shRNA against BAl1 and shRNA-resistant wild-type BAl1 (Rescue), or shRNA against BAl1 and shRNA-resistant BAl1. ( $\triangle$ TEV Res.). Shown are representative segments of secondary dendrites from neurons fixed at 21 DIV and stained for BAI1. 列

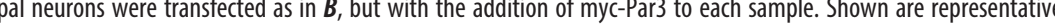
other panels. G, The fraction of neurons in each condition expressing at least one myc-Par3 punctum per dendrite tip is quantified. Data were collected from 30 neurons $(N=3)$. Data are mean \pm SEM. ${ }^{*} 0.05>p>0.01 .{ }^{* *} 0.01>p>0.001 .{ }^{* * *} p<0.001$.

$180 \mathrm{~K}$ and Tiam1 with BAI1 in neurons, whereas a scrambled control peptide had no effect. This effect was sustained for at least $1 \mathrm{~h}$ did not cause any changes in the observable levels of overall protein in the neurons (Fig. 12). These intriguing results suggest that BAI1's ability to bind, and thus regulate, Par3/Tiam1 depend on its engagement with integrin. Collectively, our results demonstrate that the adhesion-GPCR BAI1 regulates synaptogenesis in neurons by controlling the recruitment of the Par3/Tiam1 polarity complex to synaptic sites, where it regulates Racl activation and actin assembly.

\section{Discussion}

BAI1 inhibits angiogenesis via its N-terminal segment (Cork and Van Meir, 2011) and mediates phagocytosis via the Rac1-GEF 
A
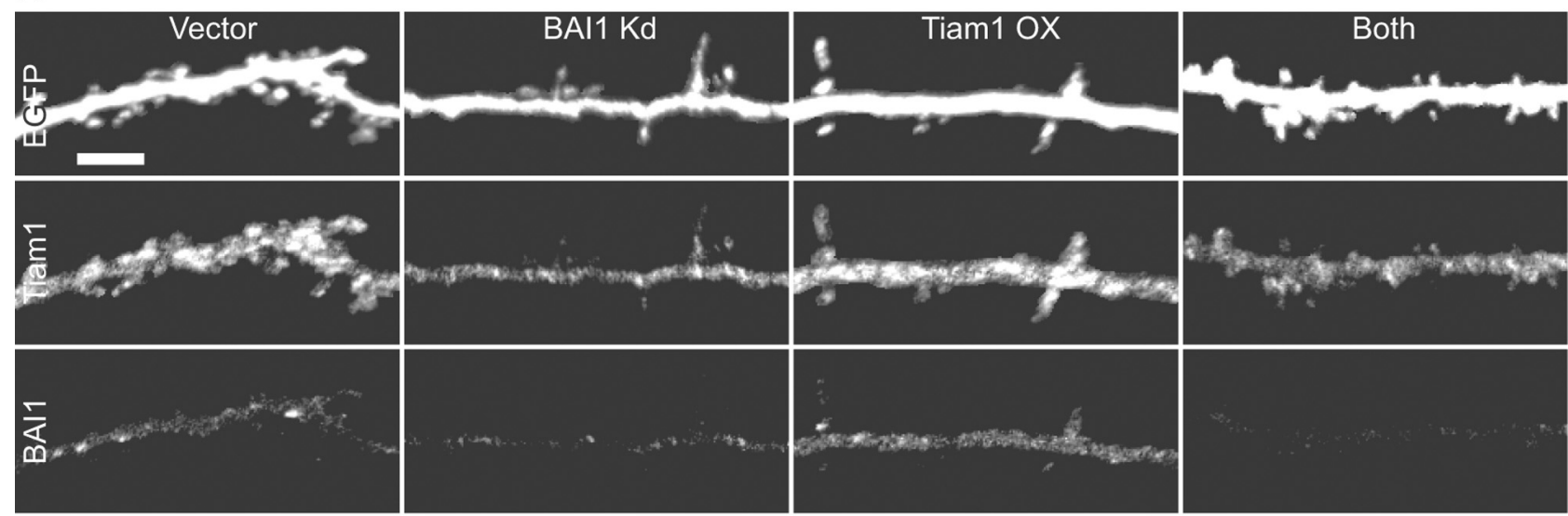

B

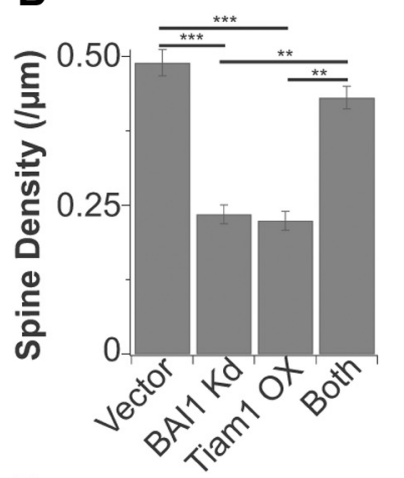

D
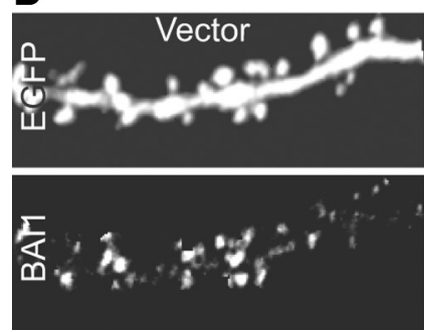

C

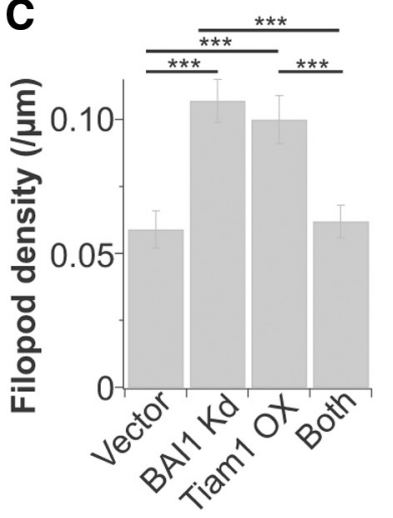

$\mathbf{E}$

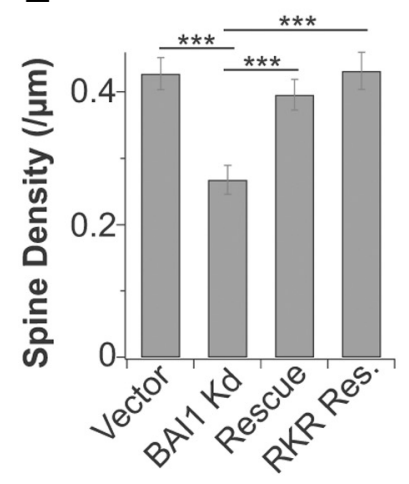

$\mathbf{F}$

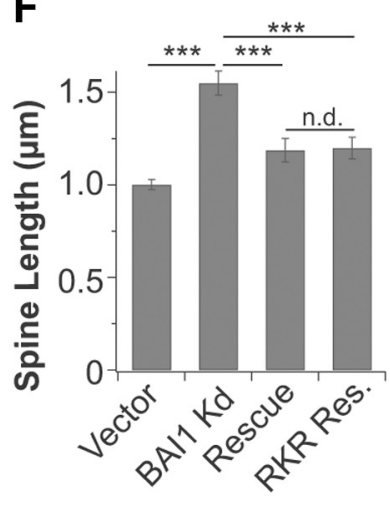

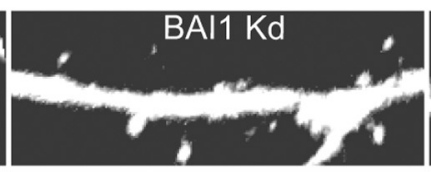
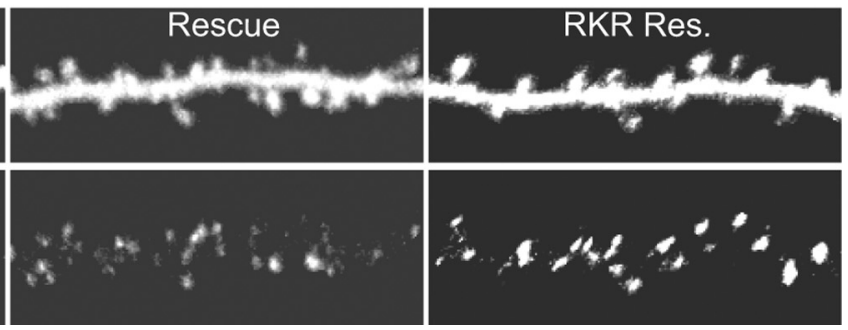

Figure 11. BAl1 signals to Rac1 through Tiam1. A, Rat hippocampal neurons were transfected at 6 DIV with EGFP and empty vectors (vector), shRNA against BAl1 (BAl1 Kd), full-length Tiam1 (Tiam1), or both. Neurons were fixed at 21 DIV and stained for BAl1 and Tiam1. Images representative of those used to calculate spine $(\boldsymbol{B})$ and filopod $(\boldsymbol{C})$ density are shown. Data were collected from 40 neurons $(N=4)$. $D$, Representative rat hippocampal neurons that were transfected at 6 DIV with EGFP and empty vectors (vector), shRNA against BAl1 (BAl1 Kd), shRNA against BAl1 and RNAi-resistant w.t. BAI1 (Rescue), and shRNA against BAl1 and RNAli-resistant BAl1 $\bullet$ RKR $\rightarrow$ AAA, which does not interact with ELM01/D0CK180. Spine density $(\boldsymbol{E})$ and length $(\boldsymbol{F})$ were calculated from images such as these $(n=50, N=5)$. Data are mean \pm SEM. ${ }^{* *} 0.01>p>0.001 .{ }^{* * *} p<0.001$. n.d., not different.

ELMO1/DOCK180 (Park et al., 2007). We now show that BAI1 also couples to Rac1 in a distinct manner to drive excitatory synaptogenesis. Specifically, BAI1 recruits the Par3/Tiam1 polarity proteins to postsynaptic sites. The following data support a connection between BAI1 and Par3/Tiam1: (1) BAI1 interacts with Par3/Tiam1; (2) Par3 and Tiam1 are mislocalized in BAI1 knockdown neurons, whereas several other proteins are not; a BAI1 mutant that does not interact with Par3 or Tiam1 in vitro rescues neither (3) BAI1 knockdown spine phenotypes nor (4) Par3 localization in neurons; (5) Tiam1 overexpression rescues BAI1 knockdown spine phenotypes, and (6) ligand binding regulates BAI1's interaction with Par3/Tiam1. Furthermore, we demonstrate that BAI1's ability to regulate synaptogenesis is completely separate from its ability to drive phagocytosis through ELMO/DOCK180/Rac1. We conclude that BAI1 regulates excitatory synapse development by recruiting the Par3/Tiam 1 polarity complex to synaptic sites, inducing polarized Racl activation and cytoskeletal remodeling. Although BAI1 is necessary for spine and synapse formation, it is not sufficient. Mild overexpression of BAI1 that preserves its localization to spines (Fig. 1E) has no detectable phenotype and expression of high levels that delocalize BAI1 lead to decreased spine density and increased spine length, suggesting a dominant negative effect (data not shown).

BAI1 primarily affects Par3 and Tiam1 via their localizations, as BAI1 knockdown caused marked changes therein. We detected no differences in Par3 or Tiam1 levels, although there may have been small changes below the threshold of detection. In contrast, PSD95 levels decreased throughout BAI1 knockdown neurons. Further, the spine/dendritic shaft gradient of PSD95 was unchanged by BAI1 knockdown. These differences between Par3/ Tiam1 and PSD95 emphasize the specificity of BAI1's effect on Par3/Tiam1. Many mechanisms localize Par3, including phosphoinositides (Krahn et al., 2010), junctional proteins (Itoh et al., 2001; Takekuni et al., 2003), phosphorylation (Takekuni et al., 
2003; Choi et al., 2007), and kinesin II (Nishimura et al., 2004). Signaling pathways target these mechanisms, but only BAI1 directly transduces extracellular signals. This ability to transmit information directly to Par3/Tiam1 would be particularly important in the regulation of synapses, which undergo remodeling throughout life.

That BAI1 associates with both Par3/ Tiam1 and ELMO/DOCK180 is surprising. Why should two separate Racl-activating modules be required downstream of the same receptor to relay signals to the same small GTPase? We and others have emphasized that Rho-family GTPase signaling depends on the precise spatiotemporal nature of the signal (Govek et al., 2005; Kiraly et al., 2010; Tolias et al., 2011). Genes encoding Rho-family GEFs greatly exceed those encoding Rho-family GTPases, and a key reason seems to be that GEFs serve as scaffolds that recruit specific receptors, effectors, and signal terminators (Tolias et al., 2011). Tiam1 is distinguished by its collaboration with the PAR polarity complex and the synaptic adaptor proteins spinophilin and IRSp53 (Rajagopal et al., 2010), whereas DOCK180/ELMO1 interacts with the scaffold CrkII (Kiyokawa et al., 1998), which binds to the focal adhesion-associated proteins p130Cas and paxillin and to ERM actin-membrane linker proteins (Miyamoto and Yamauchi, 2010). Thus, these Rac1-GEFs create distinct microdomains where Rac1 signaling takes place, resulting in different effects. BAI1 might select between these alternative pathways using its many ligand-binding sites. The binding of different ligand combinations could result in the recruitment of specific Rac-GEFs, leading to a diversity of pathways mediated by this single receptor.

Our results also shed light on the role of Par3 isoforms. Par3 exists as three main isoforms: full-length protein $(180 \mathrm{kDa})$, a 150 $\mathrm{kDa}$ isoform, and a $100 \mathrm{kDa}$ isoform lacking the $\mathrm{PKC} \zeta$-binding site (Lin et al., 2000). Par3-180K predominates in the brain, and Par3-100K is also detectable (Lin et al., 2000) (Fig. 7F). The roles of these two isoforms are not well understood, although both can rescue spine defects caused by Par3 knockdown (Zhang and Macara, 2006). Near the peak of synaptogenesis, BAI1 interacts almost exclusively with Par3-100K, thus concentrating it in BAI1 immunoprecipitates (Fig. $7 F$ ). With maturity, the BAI1/Par3$180 \mathrm{~K}$ interaction increases. Treatment with our RGD peptide increases the BAI1/Par3-180K interaction (Fig. 12), although there is no change in the BAI1/Par3-100K interaction (data not shown). Although we cannot yet delineate the roles of these two isoforms, our results indicate a model in which to explore this question. Because a key difference between the isoforms is their ability to bind PKC $\zeta$ (Lin et al., 2000), our results suggest that the synaptic BAI1/Par3/Tiam1 complex comes to regulate PKC $\zeta$ late in development. This switch could enable BAI1 to suppress signaling by the small GTPase RhoA, a negative regulator of spine formation and maintenance, because Par6/PKC $\zeta$ inhibits RhoA activity via p190 RhoGAP (Zhang and Macara, 2008).

Although our data suggest that BAI1/Par3/Tiam1 functions at excitatory synapses, none of these proteins localizes these exclu- sively. All three occur throughout the neuron in partially overlapping patterns, reflecting the fact that each protein plays additional roles. As noted, BAI1 interacts with ELMO1/ DOCK180 to mediate phagocytosis. Also, Tiam1 and Par3 function in several distinct neuronal processes, including axon initiation (Mertens et al., 2006), which may not involve BAI1. Although BAI1 $\cdot \Delta$ TEV binds Tiam 1 poorly in vitro, both proteins interact with a third protein, IRSp53 (Oda et al., 1999; Connolly et al., 2005). It is unknown whether IRSp53, which is spinogenic (Choi et al., 2005), participates in the BAI1/Par3/Tiam1 complex. Further study will be required to fully understand the functions and regulation of complexes involving BAI1, Tiam1, and the different isoforms of Par3.

Because BAI1 is a cell-surface receptor, it should transduce signals from its many potential ligands. Integrins are heterodimeric transmembrane proteins that bind to the extracellular matrix and regulate many cellular functions. Integrin $\alpha_{\mathrm{v}} \beta_{5}$ binds to BAI1, and this binding may play a role in the suppression of angiogenesis (Koh et al., 2004). Integrins also impact excitatory synaptogenesis: $\beta_{3}$-containing integrins bind to AMPARs and stabilize their surface expression, strengthening synapses (Pozo et al., 2012), and $\beta_{1}$-containing integrins bind to Arg kinase, stimulating p190RhoGAP, which inhibits RhoA signaling and promotes synapse stabilization (Warren et al., 2012). Activation of either integrin leads to spine remodeling (Shi and Ethell, 2006). However, $\alpha_{\mathrm{v}} \beta_{5}$ is the only known integrin ligand of BAI1 (Koh et al., 2004). Although $\beta_{5}$-integrin localizes to excitatory synapses (Shi and Ethell, 2006), its role is unknown. Our peptide copies the sequence flanking the RGD motif of BAI1 and is substantially different from the peptide that promotes $\beta_{1}$ - and $\beta_{3}$-dependent 
spine remodeling (Shi and Ethell, 2006). At our concentration, we expect it to disrupt BAI1 $/ \alpha_{\mathrm{v}} \beta_{5}$ interactions, although it could mimic the activation of $\alpha_{\mathrm{v}} \beta_{5}$ by BAIl binding (Shi and Ethell, 2006; Pozo et al., 2012). We favor the former explanation because it more simply explains how the peptide could affect BAIl's binding to other proteins. If true, this means that disrupting a $\alpha_{\mathrm{v}} \beta_{5} /$ BAI1 complex increases BAI1 binding to Tiam1/Par3-180K. Because both $\alpha_{\mathrm{v}} \beta_{5}$ and BAI1 are linked to phagocytosis (Albert et al., 2000; Park et al., 2007), this disruption could switch BAI1 from being in a complex favoring spine remodeling or retraction to a complex promoting spinogenesis. This is an exciting and testable hypothesis, although many questions remain to be addressed, including whether $\alpha_{\mathrm{v}} \beta_{5}$ is presynaptic or postsynaptic and whether other BAIl ligands are involved.

It is surprising that a large family of strongly conserved cellsurface receptors, such as A-GPCRs, would remain so little understood. That A-GPCRs are required for normal brain function cannot be doubted. A-GPCRs mediate myelination (Monk et al., 2009), axonal guidance (Steimel et al., 2010), dendritic arborization (Shima et al., 2007), and formation of the blood-brain barrier (Kuhnert et al., 2010), and have been linked to neurological diseases (DeRosse et al., 2008; Choudhry et al., 2012). However, we are only beginning to appreciate their mechanisms of action. Even the question of whether A-GPCRs are generally functional GPCRs in vivo is unresolved. Other mechanisms of action have meanwhile surfaced. The relationship between BAIl and ELMO1/DOCK180 is one of these mechanisms (Park et al., 2007), and our discovery of an independent BAI1-dependent Rac1activation module provides another.

Two A-GPCRs closely related to BAIl also function in the brain: BAI2-knock-out mice have a strong antidepressant phenotype (Okajima et al., 2011) and BAI3 is implicated in schizophrenia (DeRosse et al., 2008) and synapse elimination (Bolliger et al., 2011). Both are similar to BAIl, although they do not appear to compensate for BAI1 loss. The differences within the subfamily include the RGD motif, the extra thrombospondin repeat, a $\mathrm{C}$-terminal proline-rich region, and a truncation in the region important for interaction with heterotrimeric G-proteins, all unique to BAI1 (Nishimori et al., 1997; Shiratsuchi et al., 1997). Because of its otherwise high conservation, the BAI subfamily may represent an ideal microcosm for exploring general properties of A-GPCR biology. Because A-GPCRs regulate critical functions throughout the nervous system and are present on the cell surface, a thorough understanding of their biology should yield tools for manipulating these functions. This could result in treatments for mental diseases, possibly even when defective A-GPCR signaling is not etiological for the disorder.

\section{References}

Albert ML, Kim JI, Birge RB (2000) Alphavbeta5 integrin recruits the CrkiiDock180-Racl complex for phagocytosis of apoptotic cells. Nat Cell Biol 2:899-905. CrossRef Medline

Anderson TR, Shah PA, Benson DL (2004) Maturation of glutamatergic and gabaergic synapse composition in hippocampal neurons. Neuropharmacology 47:694-705. CrossRef Medline

Benarroch EE (2007) $\rho$ GTPases: role in dendrite and axonal growth, mental retardation, and axonal regeneration. Neurology 68:1315-1318. CrossRef Medline

Bolliger MF, Martinelli DC, Sudhof TC (2011) The cell-adhesion G proteincoupled receptor Bai3 is a high-affinity receptor for Clq-like proteins. Proc Natl Acad Sci U S A 108:2534-2539. CrossRef Medline

Bosch M, Hayashi Y (2012) Structural plasticity of dendritic spines. Curr Opin Neurobiol 22:383-388. CrossRef Medline

Choi J, Ko J, Racz B, Burette A, Lee JR, Kim S, Na M, Lee HW, Kim K, Weinberg RJ, Kim E (2005) Regulation of dendritic spine morphogen- esis by insulin receptor substrate 53 , a downstream effector of Racl and Cdc42 small GTPases. J Neurosci 25:869-879. CrossRef Medline

Choi KW, Nam SC, Mukhopadhyay B (2007) Par-1 and Pp2a: Yin-Yang of Bazooka localization. Fly 1:235-237. Medline

Choudhry Z, Sengupta SM, Grizenko N, Fortier ME, Thakur GA, Bellingham J, Joober R (2012) LPHN3 and attention-deficit/hyperactivity disorder: interaction with maternal stress during pregnancy. J Child Psychol Psychiatry 53:892-902. CrossRef Medline

Connolly BA, Rice J, Feig LA, Buchsbaum RJ (2005) Tiam1-Irsp53 complex formation directs specificity of Rac-mediated actin cytoskeleton regulation. Mol Cell Biol 25:4602-4614. CrossRef Medline

Cork SM, Van Meir EG (2011) Emerging roles for the BAI1 protein family in the regulation of phagocytosis, synaptogenesis, neurovasculature, and tumor development. J Mol Med (Berl) 89:743-752. CrossRef Medline

Das S, Owen KA, Ly KT, Park D, Black SG, Wilson JM, Sifri CD, Ravichandran KS, Ernst PB, Casanova JE (2011) Brain angiogenesis inhibitor 1 (BAI1) is a pattern recognition receptor that mediates macrophage binding and engulfment of Gram-negative bacteria. Proc Natl Acad Sci U S A 108:2136-2141. CrossRef Medline

DeRosse P, Lencz T, Burdick KE, Siris SG, Kane JM, Malhotra AK (2008) The genetics of symptom-based phenotypes: toward a molecular classification of schizophrenia. Schizophr Bull 34:1047-1053. CrossRef Medline

Feige JN, Sage D, Wahli W, Desvergne B, Gelman L (2005) Pixfret, an Imagej plug-in for fret calculation that can accommodate variations in spectral bleed-throughs. Microsc Res Tech 68:51-58. CrossRef Medline

Golemis EA, Serebriiskii I, Finley RL Jr, Kolonin MG, Gyuris J, Brent R (2011) Interaction trap/two-hybrid system to identify interacting proteins. Curr Protoc Cell Biol 17:13. CrossRef Medline

Govek EE, Newey SE, Van Aelst L (2005) The role of the $\rho$ GTPases in neuronal development. Genes Dev 19:1-49. CrossRef Medline

Hedstrom KL, Xu X, Ogawa Y, Frischknecht R, Seidenbecher CI, Shrager P, Rasband MN (2007) Neurofascin assembles a specialized extracellular matrix at the axon initial segment. J Cell Biol 178:875-886. CrossRef Medline

Hinkle DE, Wiersma W, Jurs SJ (19880 Applied statistics for the behavioral sciences. Boston: Houghton Mifflin.

Itoh M, Sasaki H, Furuse M, Ozaki H, Kita T, Tsukita S (2001) Junctional adhesion molecule (Jam) binds to Par-3: a possible mechanism for the recruitment of Par-3 to tight junctions. J Cell Biol 154:491-497. CrossRef Medline

Kiraly DD, Eipper-Mains JE, Mains RE, Eipper BA (2010) Synaptic plasticity, a symphony in GEF. ACS Chem Neurosci 1:348-365. CrossRef Medline

Kiyokawa E, Hashimoto Y, Kurata T, Sugimura H, Matsuda M (1998) Evidence that DOCK180 up-regulates signals from the Crkii-p130(Cas) complex. J Biol Chem 273:24479-24484. CrossRef Medline

Koh JT, Kook H, Kee HJ, Seo YW, Jeong BC, Lee JH, Kim MY, Yoon KC, Jung S, Kim KK (2004) Extracellular fragment of brain-specific angiogenesis inhibitor 1 suppresses endothelial cell proliferation by blocking alphavbeta5 integrin. Exp Cell Res 294:172-184. CrossRef Medline

Komatsu N, Aoki K, Yamada M, Yukinaga H, Fujita Y, Kamioka Y, Matsuda M (2011) Development of an optimized backbone of fret biosensors for kinases and GTPases. Mol Biol Cell 22:4647-4656. CrossRef Medline

Krahn MP, Klopfenstein DR, Fischer N, Wodarz A (2010) Membrane targeting of bazooka/Par-3 is mediated by direct binding to phosphoinositide lipids. Curr Biol 20:636-642. CrossRef Medline

Kuhnert F, Mancuso MR, Shamloo A, Wang HT, Choksi V, Florek M, Su H, Fruttiger M, Young WL, Heilshorn SC, Kuo CJ (2010) Essential regulation of CNS angiogenesis by the orphan G protein-coupled receptor Gpr124. Science 330:985-989. CrossRef Medline

Lin D, Edwards AS, Fawcett JP, Mbamalu G, Scott JD, Pawson T (2000) A mammalian Par-3-Par-6 complex implicated in Cdc42/Racl and Apkc signalling and cell polarity. Nat Cell Biol 2:540-547. CrossRef Medline

Mertens AE, Roovers RC, Collard JG (2003) Regulation of Tiam1-Rac signalling. FEBS Lett 546:11-16. CrossRef Medline

Mertens AE, Pegtel DM, Collard JG (2006) Tiam1 takes part in cell polarity. Trends Cell Biol 16:308-316. CrossRef Medline

Miyamoto Y, Yamauchi J (2010) Cellular signaling of dock family proteins in neural function. Cell Signal 22:175-182. CrossRef Medline

Monk KR, Naylor SG, Glenn TD, Mercurio S, Perlin JR, Dominguez C, Moens CB, Talbot WS (2009) A G protein-coupled receptor is essential 
for Schwann cells to initiate myelination. Science 325:1402-1405. CrossRef Medline

Nishimori H, Shiratsuchi T, Urano T, Kimura Y, Kiyono K, Tatsumi K, Yoshida S, Ono M, Kuwano M, Nakamura Y, Tokino T (1997) A novel brain-specific p53-target gene, BAI1, containing thrombospondin type 1 repeats inhibits experimental angiogenesis. Oncogene 15:2145-2150. CrossRef Medline

Nishimura T, Kato K, Yamaguchi T, Fukata Y, Ohno S, Kaibuchi K (2004) Role of the Par-3-Kif3 complex in the establishment of neuronal polarity. Nat Cell Biol 6:328-334. CrossRef Medline

Oda K, Shiratsuchi T, Nishimori H, Inazawa J, Yoshikawa H, Taketani Y, Nakamura Y, Tokino T (1999) Identification of BAIAP2 (BAIassociated protein 2), a novel human homologue of hamster IRSp53, whose SH3 domain interacts with the cytoplasmic domain of BAI1. Cytogenet Cell Genet 84:75-82. CrossRef Medline

Ohno S (2001) Intercellular junctions and cellular polarity: the Par-APKC complex, a conserved core cassette playing fundamental roles in cell polarity. Curr Opin Cell Biol 13:641-648. CrossRef Medline

Okajima D, Kudo G, Yokota H (2011) Antidepressant-like behavior in brain-specific angiogenesis inhibitor 2-deficient mice. J Physiol Sci 61:4754. CrossRef Medline

Park D, Tosello-Trampont AC, Elliott MR, Lu M, Haney LB, Ma Z, Klibanov AL, Mandell JW, Ravichandran KS (2007) BAI1 is an engulfment receptor for apoptotic cells upstream of the ELMO/DOCK180/Rac module. Nature 450:430-434. CrossRef Medline

Penzes P, Cahill ME, Jones KA, VanLeeuwen JE, Woolfrey KM (2011) Dendritic spine pathology in neuropsychiatric disorders. Nat Neurosci 14: 285-293. CrossRef Medline

Pozo K, Cingolani LA, Bassani S, Laurent F, Passafaro M, Goda Y (2012) $\beta 3$ integrin interacts directly with Glua2 AMPA receptor subunit and regulates AMPA receptor expression in hippocampal neurons. Proc Natl Acad Sci U S A 109:1323-1328. CrossRef Medline

Rajagopal S, Ji Y, Xu K, Li Y, Wicks K, Liu J, Wong KW, Herman IM, Isberg RR, Buchsbaum RJ (2010) Scaffold proteins IRSp53 and spinophilin regulate localized Rac activation by T-lymphocyte invasion and metastasis protein 1 (Tiam1). J Biol Chem 285:18060-18071. CrossRef Medline

Ramakers GJ (2002) $\rho$ proteins, mental retardation and the cellular basis of cognition. Trends Neurosci 25:191-199. CrossRef Medline

Shamah SM, Lin MZ, Goldberg JL, Estrach S, Sahin M, Hu L, Bazalakova M, Neve RL, Corfas G, Debant A, Greenberg ME (2001) EphA receptors regulate growth cone dynamics through the novel guanine nucleotide exchange factor ephexin. Cell 105:233-244. CrossRef Medline

Shi SH, Jan LY, Jan YN (2003) Hippocampal neuronal polarity specified by spatially localized Mpar3/Mpar6 and PI3-kinase activity. Cell 112:63-75. CrossRef Medline

Shi Y, Ethell IM (2006) Integrins control dendritic spine plasticity in hippocampal neurons through NMDA receptor and $\mathrm{Ca}^{2+} /$ calmodulindependent protein kinase II-mediated actin reorganization. J Neurosci 26:1813-1822. CrossRef Medline

Shima Y, Kawaguchi SY, Kosaka K, Nakayama M, Hoshino M, Nabeshima Y,
Hirano T, Uemura T (2007) Opposing roles in neurite growth control by two seven-pass transmembrane cadherins. Nat Neurosci 10:963-969. CrossRef Medline

Shiratsuchi T, Nishimori H, Ichise H, Nakamura Y, Tokino T (1997) Cloning and characterization of Bai2 and Bai3, novel genes homologous to brain-specific angiogenesis inhibitor 1 (BAI1). Cytogenet Cell Genet 79: 103-108. CrossRef Medline

Spindler SR, Hartenstein V (2011) Bazooka mediates secondary axon morphology in Drosophila brain lineages. Neural Dev 6: 16. CrossRef Medline

Steimel A, Wong L, Najarro EH, Ackley BD, Garriga G, Hutter H (2010) The flamingo ortholog Fmi-1 controls pioneer-dependent navigation of follower axons in C. elegans. Development 137:3663-3673. CrossRef Medline

Tada T, Sheng M (2006) Molecular mechanisms of dendritic spine morphogenesis. Curr Opin Neurobiol 16:95-101. CrossRef Medline

Takekuni K, Ikeda W, Fujito T, Morimoto K, Takeuchi M, Monden M, Takai Y (2003) Direct binding of cell polarity protein Par-3 to cell-cell adhesion molecule nectin at neuroepithelial cells of developing mouse. J Biol Chem 278:5497-5500. CrossRef Medline

Tolias KF, Bikoff JB, Burette A, Paradis S, Harrar D, Tavazoie S, Weinberg RJ, Greenberg ME (2005) The Racl-Gef Tiaml couples the NMDA receptor to the activity-dependent development of dendritic arbors and spines. Neuron 45:525-538. CrossRef Medline

Tolias KF, Bikoff JB, Kane CG, Tolias CS, Hu L, Greenberg ME (2007) The Rac1 guanine nucleotide exchange factor Tiam1 mediates Ephb receptordependent dendritic spine development. Proc Natl Acad Sci U S A 104: 7265-7270. CrossRef Medline

Tolias KF, Duman JG, Um K (2011) Control of synapse development and plasticity by $\rho$ GTPase regulatory proteins. Prog Neurobiol 94:133-148. CrossRef Medline

Warren MS, Bradley WD, Gourley SL, Lin YC, Simpson MA, Reichardt LF, Greer CA, Taylor JR, Koleske AJ (2012) Integrin beta1 signals through Arg to regulate postnatal dendritic arborization, synapse density, and behavior. J Neurosci 32:2824-2834. CrossRef Medline

Welchman DP, Mathies LD, Ahringer J (2007) Similar requirements for Cdc-42 and the Par-3/Par-6/Pkc-3 complex in diverse cell types. Dev Biol 305:347-357. CrossRef Medline

Yona S, Lin HH, Siu WO, Gordon S, Stacey M (2008) Adhesion-GPCRs: emerging roles for novel receptors. Trends Biochem Sci 33:491-500. CrossRef Medline

Zhang H, Macara IG (2006) The polarity protein Par-3 and Tiaml cooperate in dendritic spine morphogenesis. Nat Cell Biol 8:227-237. CrossRef Medline

Zhang H, Macara IG (2008) The Par-6 polarity protein regulates dendritic spine morphogenesis through P190 $\rho$ gap and the $\rho$ GTPase. Dev Cell 14:216-226. CrossRef Medline

Zhu D, Hunter SB, Vertino PM, Van Meir EG (2011) Overexpression of Mbd2 in glioblastoma maintains epigenetic silencing and inhibits the antiangiogenic function of the tumor suppressor gene BAI1. Cancer Res 71:5859-5870. CrossRef Medline 